\title{
GESTÃO E ESTRATÉGIA AMBIENTAL: UM ESTUDO BIBLIOMÉTRICO SOBRE O INTERESSE DO TEMA NOS PERIÓDICOS ACADÊMICOS BRASILEIROS
}

\author{
Simone Sehnem \\ simonesehnem_adm@yahoo.com.br \\ Universidade do Vale do Itajaí - Biguaçu, SC / Brasil \\ Murilo de Alencar Souza Oliveira \\ malencar@fiocruz.br \\ Universidade do Vale do Itajaí - Biguaçu, SC / Brasil \\ Elaine Ferreira \\ elainef@univali.br \\ Universidade do Vale do Itajaí - Itajaí, SC / Brasil \\ Adriana Marques Rossetto \\ arossetto@univali.br \\ Universidade do Vale do Itajaí - Itajaí, SC / Brasil
}

Recebido em 06/10/2010

Aprovado em 01/07/2011

Disponibilizado em 01/08/2012

Avaliado pelo sistema double blind review

Revista Eletrônica de Administração

Editor: Luís Felipe Nascimento

ISSN 1413-2311 (versão on-line)

Editada pela Escola de Administração da Universidade Federal do Rio Grande do Sul.

Periodicidade: Quadrimestral

Sistema requerido: Adobe Acrobat Reader.

\section{RESUMO}

Este trabalho objetivou identificar a evolução do interesse de publicação da administração nas questões da gestão ambiental, estratégia ambiental, desempenho ambiental e avaliação estratégica ambiental (em português, inglês ou espanhol), através da verificação de artigos com estas temáticas em periódicos da área. Realizou-se um estudo bibliométrico, com abordagem quantitativa, em 44 periódicos brasileiros classificados em 2008 pelo sistema Qualis/CAPES - Coordenação de Aperfeiçoamento de Pessoal de Nível Superior, como A1, A2, B1 e B2, para a área de Administração, Ciências Contábeis e Turismo. Foram pesquisadas 1.203 edições disponibilizadas eletronicamente, entre 2000 e 2009, com a identificação de 113 artigos, de 22 periódicos, que citaram algum dos termos de busca no corpo de texto. Os artigos foram analisados com base nos seguintes parâmetros: identificação do periódico; ocorrência dos termos-chave; ano de publicação; e autoria. Identificou-se que apenas cinco periódicos publicaram 54,86\% dos artigos selecionados: REAd - Rev. Eletrônica de Administração (15,04\%), G\&P - Gestão \& Produção (11,50\%), RAP - Rev. de Administração Pública (11,50\%), CAD - Cadernos EBAPE.BR (9,74\%) e PROD - Produção (7,08\%). O termo chave 'Gestão Ambiental' foi encontrado no título de 38 dos artigos, é citado como palavra-chave em 64 e está presente no corpo de texto de 111. Já 'Avaliação

REAd I Porto Alegre - Edição 72 - N 2 - maio/agosto 2012 - p. 468-493 
Simone Sehnem, Murilo de Alencar Souza Oliveira, Elaine Ferreira \& Adriana Marques Rossetto

Ambiental Estratégica' somente foi citado em 2 artigos da amostra. Os anos de maior publicação dos artigos foram 2006 (20) e 2009 (24). Os autores que mais publicaram tiveram participação em 7 artigos diferentes da amostra. Observou-se que de 2000 a 2009 houve bom crescimento de periódicos brasileiros e número de artigos publicados que citaram os termos pesquisados, inclusive com edições especiais sobre a questão ambiental, porém com difusão pouco significativa nas publicações brasileiras, haja vista que somente houve identificação dos termos-chave na razão de um artigo para cada 10 edições analisadas. Espera-se que este trabalho possa contribuir, a partir da identificação quantitativa dos artigos, periódicos e autores que citaram os termos de busca desta pesquisa (conforme listagem do Apêndice 1), para configurar o estado da arte e divulgar a fundamentação teórica nacional sobre a temática da questão ambiental relacionada a gestão, estratégia e o desempenho organizacionais.

Palavras-chave: Gestão Ambiental, Estratégia Ambiental, Desempenho Ambiental, Avaliação Estratégica Ambiental, Bibliométrico.

\title{
ENVIRONMENTAL MANAGEMENT AND STRATEGY: A BIBLIOMETRIC STUDY ON THE THEME OF INTEREST IN BRAZILIAN ACADEMIC JOURNALS
}

\begin{abstract}
This study aimed to identify changes in the interest of the administration area on issues of environmental management, environmental strategy, environmental performance and strategic environmental assessment (in Portuguese, English or Spanish) by checking the articles with these themes in journals. We carried out a bibliometric study with a quantitative approach, in 44 Brazilian journals classified by the system in 2008 Qualis/CAPES - Coordination for the Improvement of Higher Education Personnel, such as A1, A2, B1 and B2, to the area of Administration, Accounting and Tourism. We surveyed 1203 editions available electronically, between 2000 and 2009, with the identification of 113 articles in 22 journals, citing some of the search terms in the body text. Articles were evaluated using the following parameters: identification of the journal, the occurrence of key terms, date of publication, and authorship. It was identified that only five journals published $54.86 \%$ of articles selected: REAd Electronic Administration Rev. (15.04\%), G \& P - Production \& Management (11.50\%), RAP - Rev. of Public Administration (11.50\%), CAD - Notebooks EBAPE.BR (9.74\%) and PROD - Production (7.08\%). The key term 'Environmental Management' was found in title 38 of the articles, is cited as a keyword in 64 and present in the body text 111 . Have 'Strategic Environmental Assessment' was only mentioned in two articles in the sample. The years of publication of the articles were higher in 2006 (20) and 2009 (24). Authors who have published more have participated in seven different articles of the sample. It was noted that from 2000 to 2009 there was a good growth of Brazilian magazines and number of published articles that cited the search terms, including special issues on the environmental issue, but with negligible diffusion in Brazilian publications, since it was identified only of key terms in respect of an article for each ten issues examined. It is hoped that this work can contribute, from the quantitative identification of articles, journals and authors that have cited this search query terms (as listing in Annex 1), to set the state of the art and disclose the theoretical foundation's national theme of environmental issues related to management, strategy and organizational performance.
\end{abstract}

REAd I Porto Alegre - Edição 72 - N 2 - maio/agosto 2012 - p. 468-493 
Gestão e estratégia ambiental: um estudo bibliométrico sobre o interesse do tema nos periódicos acadêmicos brasileiros

Keywords: Environmental Management, Environmental Strategy, Environmental Performance, Strategic Environmental Assessment, bibliometrics.

\title{
GESTIÓN AMBIENTAL Y ESTRATEGIA: UN ESTUDIO BIBLIOMÉTRICO SOBRE EL TEMA DE INTERÉS EN REVISTAS ACADÉMICA BRASILEÑA
}

\begin{abstract}
RESUMEN
Este estudio tuvo como objetivo identificar los cambios en el interés de la zona de administración en temas de gestión ambiental, la estrategia ambiental, desempeño ambiental y evaluación ambiental estratégica (en Portugués, Inglés o español) marcando los artículos de estos temas en las revistas. Se realizó un estudio bibliométrico con enfoque cuantitativo, en 44 periódicos nacionales clasificados por el sistema en 2008 Qualis/CAPES - Coordinación de Perfeccionamiento de Personal de Nivel Superior, tal como A1, A2, B1 y B2, para el área de Administración, Contabilidad y Turismo. Se encuestó a 1.203 ediciones en formato electrónico, entre 2000 y 2009, con la identificación de 113 artículos en 22 revistas, citando algunos de los términos de búsqueda en el texto del cuerpo. Los artículos fueron evaluados utilizando los siguientes parámetros: identificación de la revista, la ocurrencia de los términos clave, fecha de publicación, y la autoría. Se identificó que sólo cinco revistas publicadas 54,86\% de los artículos seleccionados: REAd - Administración Electrónica Rev. (15,04\%), G \& P - Producción y Gestión (11,50\%), RAP - Rev. de Administración Pública (11,50\%), CAD - EBAPE.BR Portátiles (9,74\%) y PROD - Producción (7,08\%). El término clave 'Gestión Ambiental' se encuentra en el título 38 de los artículos, se cita como una palabra clave en el 64 y presente en el texto del cuerpo 111. Tener 'Evaluación Ambiental Estratégica' sólo se menciona en dos artículos en la muestra. Los años de la publicación de los artículos fueron mayores en 2006 (20) y 2009 (24). Los autores que han publicado más han participado en siete diferentes artículos de la muestra. Se señaló que desde 2000 hasta 2009 hubo un buen crecimiento de las revistas brasileñas y el número de artículos publicados que citan los términos de búsqueda, incluyendo números especiales sobre el tema ambiental, pero con la difusión insignificante en publicaciones brasileñas, desde que se identificó sólo de los términos clave en relación con un artículo de cada diez cuestiones examinadas. Se espera que este trabajo puede contribuir, desde la identificación cuantitativa de los artículos, revistas y autores que han citado este términos de la consulta de búsqueda (como la inclusión en el apêndice 1), para establecer el estado de la técnica y dar a conocer la fundamentación teórica de nacionales tema de las cuestiones ambientales relacionadas con la gestión, la estrategia y el desempeño organizacional.
\end{abstract}

Palabras clave: Gestión del Medio Ambiente, Estrategia Ambiental, Desempeño Ambiental, Evaluación Ambiental Estratégica, bibliometría.

\section{INTRODUÇÃO}

Diante das questões ambientais, exige-se na atualidade que as empresas tenham uma postura proativa na maneira de operar seus negócios. Necessário se faz desenvolver estratégias que antecipem formas de lidar com os problemas ambientais. Nesse sentido,

REAd I Porto Alegre - Edição 72 - Nº 2 - maio/agosto 2012 - p. 468-493 
Simone Sehnem, Murilo de Alencar Souza Oliveira, Elaine Ferreira \& Adriana Marques Rossetto

Sanches (2000) salienta que é fundamental utilizar as tecnologias ambientais no intuito de assegurar o desenvolvimento econômico, produtivo e ambiental.

Rohrich e Cunha (2004) afirmam que o Brasil tem vislumbrado a destruição ambiental como um preço aceitável a ser pago pelo progresso econômico ou como uma prioridade menor, considerando suas necessidades. Todavia, conforme Maimon (1994), desde a década de 80 a responsabilidade ambiental passou a ser vista como uma necessidade de sobrevivência, e tornou-se um mercado promissor, um novo produto/serviço a ser comercializado. Sanches (2000) destaca que o meio ambiente tem se tornado elemento vital na criação de novos paradigmas de concorrência industrial e, assim, emerge como importante questão para o estabelecimento dos rumos dos mercados e das sociedades locais e globais.

Maimon (1994) salienta ainda que a conscientização da população e a expansão do movimento ambientalista corroboram na pressão aos órgãos de regulação no que tange ao controle e monitoramento da poluição, bem como na consolidação de um aparato institucional e legal da política ambiental. Todavia, ainda impera um conceito aético-ambiental nas empresas, onde o pior dos poluidores pode se tornar o modelo de virtude ambiental, desde que os aspectos técnico-econômicos e mercadológicos apontem para essa direção.

Ebenkamp (2008) menciona que as pessoas estão interessadas em tornarem-se 'verdes', mas elas não necessariamente sabem o que fazer de forma específica. E quando as pessoas estão confusas, elas não fazem nada. $\mathrm{O}$ autor destaca que o mercado está pronto e é tempo da empresa mostrar a sua verdadeira cor. Vithessonthi (2009) complementa afirmando que espera-se que as organizações verdes consigam satisfazer as expectativas tanto do mundo dos negócios quanto do mundo ecológico, e lidem bem com as pressões conflitantes entre estas duas esferas. Essa assertiva é endossada por Bockman, Razzouk e Sirotnik (2009) que salientam que a população de todas as faixas etárias, níveis de educação e níveis sócioeconômicos parece compartilhar de preocupações sobre o meio ambiente, e sugere que ele deve ter prioridade sobre o crescimento econômico. Entretanto, os autores mencionam que ambientalistas, governo, e mesmo as empresas estão a angariar uma orientação verde, diante das preocupações ambientais; os consumidores estão perplexos com a ligação entre a verdade e os "verdes folheados" ou "verdes-proclamados" nas estratégias dessas organizações.

Diante desse contexto, o propósito deste artigo foi identificar a publicação de artigos acadêmicos em periódicos nacionais no período de 2000 a 2009, que citam os termos: Gestão Ambiental, Estratégia Ambiental, Desempenho Ambiental e Avaliação Estratégica Ambiental (em português, inglês ou espanhol) como forma de verificar como a área de administração,

REAd I Porto Alegre - Edição 72 - N 2 - maio/agosto 2012 - p. 468-493 
Gestão e estratégia ambiental: um estudo bibliométrico sobre o interesse do tema nos periódicos acadêmicos brasileiros

através destes veículos de divulgação, está se posicionando em relação ao tema e se o mesmo tem adquirido importância no debate acadêmico. Além da introdução, o artigo possui um item com o embasamento teórico que contempla informações sobre a questão ambiental, as iniciativas empresariais estratégicas relacionadas ao meio ambiente e a necessidade de sensibilização e comprometimento da população diante dos problemas ambientais. Os itens subseqüentes apresentam a metodologia utilizada na pesquisa, os dados coletados por meio do estudo bibliométrico e a análise dos mesmos. Por fim, são apresentadas as conclusões deste estudo e em apêndice segue a relação de artigos identificados.

\section{ORGANIZAÇÕES EMPRESARIAIS E A VARIÁVEL AMBIENTAL}

Conforme reconhecido por Ambec e Lanoie (2008), os sistemas naturais podem ser especialmente vulneráveis à atividade humana devido à limitada capacidade adaptativa e, alguns destes sistemas podem sofrer danos significativos e irreversíveis. Mencionam também que os recorrentes alertas de chuvas ácidas, buracos na camada de ozônio, aquecimento global e a perda de biodiversidade estão entre as crescentes provas de que essa é realmente uma calamidade possível e que ocorre numa velocidade mais rápida do que cientistas previram. É por isso que os ambientalistas em particular, e à população em geral, acreditam que a abordagem de gestão dos negócios usual é preocupante (AMBEC, LANOIE, 2008).

Reflexões dessa natureza geraram discussões acerca da capacidade de sustentabilidade do planeta, ou seja, a relação entre o processo de desenvolvimento da sociedade e o meio ambiente. A carga provocada pela atividade humana em razão de mudanças culturais, tecnológicas, de valores, aspirações e desejos passa a ser demasiada e, em consequiência, o sistema natural apresenta alguns sinais de esgotamento, conforme Bellen (2005). Nas últimas 3 décadas ocorreram mobilizações internacionais capitaneadas pela Organização das Nações Unidas/ONU sobre esta questão, dentre elas cita-se: a publicação do relatório Brundtland em 1987; a Cúpula da Terra - Eco 92, ocorrida no Rio de Janeiro em 1992, com a proposição do documento Agenda 21 (MULLER-PLATEMBERG, 1998); a Cúpula Mundial sobre Desenvolvimento Sustentável, sediada em Joanesburgo em 2002; e mais recentemente a $15^{\text {a }}$ Conferência das Nações Unidas sobre Mudança do Clima - COP 15 ocorrida em Copenhage em 2009. Tais encontros/conferências/publicações apresentaram como propósito a busca de consenso na avaliação geral das condições ambientais do planeta e o estabelecimento de prioridades e mecanismos para ações globais, regionais e nacionais, implementadoras de um

REAd I Porto Alegre - Edição 72 - N 2 - maio/agosto 2012 - p. 468-493 
Simone Sehnem, Murilo de Alencar Souza Oliveira, Elaine Ferreira \& Adriana Marques Rossetto

novo modelo de desenvolvimento: socialmente justo, com equilíbrio ecológico e viabilidade econômica.

Diante disso, as atividades produtivas precisam ser adaptadas para amenizar os impactos ambientais que ocasionam. Uma das alternativas possíveis é incluir a variável ambiental na estratégia de negócios das empresas. Porém, Miranda, Samudio e Dourado (1997) enfatizam que na abordagem tradicional, a solução dos problemas ambientais é vista como obrigação, pois as empresas só consideram as questões ambientais quando surgem leis restritivas as suas operações produtivas.

Azzone e Bertelè (1994) bem como Porter e Van der Linde (1995), mencionam que os principais efeitos provocados pelas regulamentações estão diretamente relacionados com a pressão para motivar a empresa a mudar: modificação de seu processo/produto a fim de continuar sua produção; estabelecimento de metas e períodos de tempo para a realização de qualquer mudança, porém, quase sempre esse tempo é superior ao necessário para efetuar a modificação; e, em alguns países alertas e orientação para as possíveis ineficiências de recursos e as áreas potenciais para a melhoria tecnológica. Nesse cenário, existe um predomínio da abordagem reativa para o tratamento dos problemas ambientais, haja vista que as empresas apresentam uma forte oposição a qualquer tipo de regulamentação. Porém, como destacam Miranda, Samudio e Dourado (1997) a abordagem reativa pode ser considerada ineficiente, sobretudo em decorrência da crescente velocidade das mudanças nos padrões ambientais. Desse modo, a empresa não pode esperar até que o novo padrão seja estabelecido por lei (nesse caso, uma abordagem reativa levaria a empresa a sair do mercado).

Por outro lado, como destaca Donaire (1995), ao pensar nas consequiências da despreocupação ambiental relacionadas ao aumento de custos e redução de lucros devido ao uso ineficiente dos recursos, perda de posição no mercado ou cessação de atividades, reconhece-se que uma posição proativa pode ser vantajosa em termos de competitividade. Neste pensamento, Miranda, Samudio e Dourado (1997) destacam a emergência dos consumidores verdes que priorizam o consumo dos produtos oriundos de empresas que adotam uma abordagem proativa concernente aos aspectos ambientais, ao reformular seus produtos, eliminar produtos tóxicos e usar processos e tecnologias limpas. Entretanto, mesmo que a empresa não atue nesse mercado de consumidores verdes, o uso da abordagem proativa pode permitir o aflorar da criatividade e das condições internas para aproveitar e transformar as restrições e ameaças ambientais em oportunidades de negócios.

REAd I Porto Alegre - Edição 72 - N 2 - maio/agosto 2012 - p. 468-493 
Gestão e estratégia ambiental: um estudo bibliométrico sobre o interesse do tema nos periódicos acadêmicos brasileiros

Nesta linha, Porter e Van der Linde (1995) têm argumentado basicamente que a melhoria do desempenho ambiental de uma empresa, pode levar a melhoria econômica ou de desempenho financeiro, e não necessariamente a um aumento no custo. Além disso, Ambec e Lanoie (2008) afirmam que a melhoria do desempenho ambiental pode conduzir a um aumento das receitas através de três canais: (a) melhor acesso a certos mercados, (b) diferenciar produtos e (c) vender tecnologias de controle de poluição. Além disso, um melhor desempenho ambiental pode levar à redução de custos em quatro categorias: (a) gestão de risco e relações com agentes externos, (b) custo dos materiais, energia e serviços; (c) custo do capital, e (d) custo do trabalho. Igualmente, a redução dos custos de material/produto ou energia pode facilitar a incorporação do ambiente em características do produto, como ajuda para desenvolver uma estratégia de diferenciação; aumento da receita; melhor desempenho ambiental, o que pode facilitar o acesso a determinados mercados mais seletivos. Sobretudo, de um modo geral, a redução da poluição e outros impactos ambientais podem melhorar a imagem de uma empresa e, em consequência, contribuir para o aumento da fidelidade dos clientes ou apoiar os esforços de vendas de seus produtos/serviços.

Miranda, Samudio e Dourado (1997) afirmam que a ênfase na oportunidade de antecipar-se ou de ser proativo em relação à questão ambiental envolve decisões estratégicas, como investimentos em pesquisa e desenvolvimento de novos produtos e processos que geram políticas, metas e planos de ação de direcionamento da empresa. Em resposta ao crescente aumento nas exigências e pressões exercidas pelos stakeholders para adoção de práticas e sistemas de gestão ambiental por parte das empresas, observa-se em geral, que nos setores em que existe mais forte pressão, as empresas se mobilizam e aceitam certificar, monitorar e controlar os impactos ambientais de seus processos produtivos. Entretanto, as empresas precisam entender que os benefícios em termos de redução de custos e das melhorias operacionais podem propiciar maior competitividade e retorno mercadológico.

Sanches (2000) salienta que o emprego de tecnologias ambientais para a gestão organizacional é elemento fundamental para assegurar o desempenho econômico, produtivo e ambiental de uma empresa industrial. Reitera também que o uso destas tecnologias relacionadas ao controle e prevenção de poluição e aos produtos e processos tem sido fator importante nas últimas décadas para assegurar a rentabilidade e competitividade empresarial.

Desta forma, a incorporação da variável ambiental na gestão e estratégia de negócios das empresas pode contribuir para a construção de uma imagem positiva junto aos clientes e ser fonte geradora de rentabilidade, vantagens e benefícios econômicos. Vithessonthi (2009)

REAd I Porto Alegre - Edição 72 - N 2 - maio/agosto 2012 - p. 468-493 
Simone Sehnem, Murilo de Alencar Souza Oliveira, Elaine Ferreira \& Adriana Marques Rossetto

aponta que desde os anos de 1990 foram realizadas várias pesquisas sobre a integração dos campos da gestão estratégica e ambiental, tais como as que enfatizaram: a aplicação de princípios e teorias estratégicas para o estudo das interações das empresas com o meio ambiente natural (STEAD, STEAD 1996; KETOLA 1997; SOUITARIS, PUJARI 1998; GOLDSTEIN 2002); as influências e pressões exercidas pelos stakeholders nas estratégias ambientais das organizações (HOFFMAN 1999; CHRISTMANN 2000; HENRIQUES, SADORSKY 1999); as implicações sobre os mercados e forças competitivas (HART 1995; NEHRT 1996); as atitudes gerenciais (CORDANO, FRIEZE; 2000); e a propensão gerencial aos riscos (SHARMA; NGUAN, 1999).

Uma das formas mais recentes desta imbricação entre estratégia e gestão ambiental é a Avaliação Ambiental Estratégica (AAE), que de forma geral consiste em uma ferramenta de planejamento ou processo formal, sistemático, flexível, democrática e abrangente de todas as formas de avaliação prévia das conseqüências e impactos ambientais. Dalal-Clayton e Sadler (1999), Nilsson e Dalkmann (2001), e também, Partidário (2002) apontam que sua finalidade está no apoio a tomada de decisões para o equacionamento ou mitigação destes impactos, bem como da integração da gestão ambiental com aspectos biofísicos, econômicos, políticos e sociais de iniciativas governamentais e privadas, como leis, políticas, planos e programas. No Brasil, para Sanchez (2010), a AAE passou a ser discutida somente nos últimos anos, mas ainda muito restrita ao meio acadêmico, sendo impulsionada em face da dificuldade de licenciamento ambiental de grandes projetos de infraestrutura e requer conciliar as características reais do contexto desta tomada de decisão - racionais, políticas, cognitivas, informacionais e comportamentais. Além disto, Nilsson e Dalkmann (2001) afirmam que deve incluir as características, forças e interesses de múltiplos atores; lidar com a complexidade e riqueza de informações, porém, frequentemente com pouco conhecimento sobre as mesmas; ir além da análise dos impactos ambientais, influenciando o processo e conteúdo das prioridades, questões e valores das decisões. Características que levem em conta a situação econômica e política local/nacional, a complexidade de sua elaboração (atendam aos interesses técnicos e políticos das diversas partes envolvidas), assim como também no nível das estruturas existentes de governo e planejamento.

Mesmo evidenciada a importância da questão ambiental e a necessidade de introduzir esta variável nas práticas de gestão e nas estratégias das organizações, percebe-se ainda pouca repercussão nos meios empresariais e poucos avanços nos meios acadêmicos em relação à disseminação da própria discussão sobre o tema, em especial no Brasil. Desta forma, torna-se

REAd I Porto Alegre - Edição 72 - Nº 2 - maio/agosto 2012 - p. 468-493 
Gestão e estratégia ambiental: um estudo bibliométrico sobre o interesse do tema nos periódicos acadêmicos brasileiros

fundamental que se identifique o estado da arte da discussão das temáticas gestão ambiental, estratégia ambiental, desempenho ambiental e avaliação estratégica ambiental no País.

\section{METODOLOGIA}

Este estudo consistiu de um levantamento bibliométrico descritivo acerca da produção científica nas temáticas de gestão ambiental, estratégia ambiental, desempenho ambiental e avaliação estratégica ambiental (em português, inglês ou espanhol), presentes nas principais revistas relativas as áreas de gestão empresarial e pública no período da década compreendida entre os anos de 2000 a 2009. O universo de pesquisa considerado abrangeu 335 periódicos classificados em 2008 como A1, A2, B1 e B2, para a área de Administração, Ciências Contábeis e Turismo, conforme apresentado pela Qualis/CAPES - Coordenação de Aperfeiçoamento de Pessoal de Nível Superior (CAPES, 2010). Esta classificação apresenta periódicos nacionais e internacionais para a área em questão, voltados para diferentes ramos do conhecimento, como: Administração, Turismo, Psicologia, Ciência da Informação, Serviço Social, Estatística, Engenharia, Economia, Saúde Pública, Antropologia, Sociologia etc.

Destaca-se, que a elaboração deste trabalho, de forma semelhante ao efetuado por Jabbour, Santos e Barbieri (2008), restringiu-se a análise de periódicos, portanto não inclui a produção científica presente em anais de congressos e eventos. Tal escolha derivou do fato que estes fóruns acadêmicos não são mais classificados pela Capes e que os trabalhos neles apresentados de maior impacto e relevância são publicados a posteriori em periódicos.

Desta forma, optou-se por uma seleção intencional dos periódicos nacionais mais expressivos para a área, o que resultou na definição de 44 revistas, a partir da qual foram pesquisadas um total de 1.203 edições disponibilizadas em formato eletrônico em sites das revistas e/ou na plataforma de pesquisa SciELO. Trata-se, portanto, de estudo com abordagem quantitativa para tratamento dos dados.

Identificou-se uma amostra de 22 periódicos nacionais em que foram encontrados 113 artigos que apresentaram ocorrência no corpo de texto dos termos-chave: Gestão Ambiental, Estratégia Ambiental, Desempenho Ambiental e Avaliação Ambiental Estratégica (em português, inglês ou espanhol). Estes artigos foram então classificados com base nos seguintes parâmetros: ocorrência dos termos-chave; identificação do periódico; ano de publicação; e autoria.

REAd I Porto Alegre - Edição 72 - N 2 - maio/agosto 2012 - p. 468-493 
Simone Sehnem, Murilo de Alencar Souza Oliveira, Elaine Ferreira \& Adriana Marques Rossetto

O enquadramento nos parâmetros estabelecidos foi efetuado a partir da busca, leitura e análise de cada artigo. Objetivou-se identificar a ocorrência da temática ambiental relacionada com a gestão e estratégia das empresas nas publicações dos trabalhos, considerando que: (i) para a variável ocorrência dos termos-chave, identificou-se a quantidade de artigos que citaram cada um dos termos-chave desta pesquisa no título, nas palavras-chaves e no corpo do texto; (ii) para a variável identificação do periódico, buscou-se apresentar o título do periódico, classificação conforme Qualis/Capes, período de pesquisa efetuada e quantidade de artigos encontrados com os termos-chave; (iii) para a variável ano de publicação, foi efetuada a identificação dos periódicos por ano de publicação dos artigos; (iv) para a variável autoria, procurou-se identificar os autores mais produtivos no período analisado, bem como apresentar os periódicos de publicação destes artigos no Brasil.

Portanto, a análise dos artigos selecionados consistiu em uma análise de conteúdo. Fez-se a contagem do número de autores que passaram a publicar, ano a ano, nas temáticas de gestão ambiental, estratégia ambiental, desempenho ambiental e avaliação estratégica ambiental. Assim, foi possível apresentar o estado da arte dos assuntos supramencionados.

\section{DISCUSSÃO E ANÁLISE DOS DADOS}

Para apresentar a variável ocorrência dos termos-chave nos artigos identificados no total de publicações desta pesquisa, foi elaborado o Quadro 01.

Quadro 1: Ocorrência dos Termos-chave nos artigos da amostra.

\begin{tabular}{ccccc}
\hline Termo-Chave & $\begin{array}{c}\text { Gestão } \\
\text { Ambiental (G) }\end{array}$ & $\begin{array}{c}\text { Desempenho } \\
\text { Ambiental (D) }\end{array}$ & $\begin{array}{c}\text { Estratégia } \\
\text { Ambiental (E) }\end{array}$ & $\begin{array}{c}\text { Avaliação Ambiental } \\
\text { Estratégica (A) }\end{array}$ \\
\hline Título & 38 & 3 & 2 & 0 \\
\hline Palavra-chave & 64 & 4 & 6 & 0 \\
\hline Texto & 111 & 57 & 22 & 2 \\
\hline \multicolumn{5}{r}{ Fonte: elaborado pelos autores, 2010. }
\end{tabular}

Destaca-se no quadro 01 que o termo 'Gestão Ambiental' compõe o título de 38 dos artigos selecionados, é palavra-chave em 64 deles, sendo citado no texto de quase todos os artigos da amostra (98,23\%). O termo 'Desempenho Ambiental' aparece em metade dos artigos $(50,4 \%)$, mas somente consta em 3 títulos e aparece como palavra-chave somente quatro vezes. Já 'Estratégia Ambiental' é citado em cerca de um quinto (19,5\%) dos artigos, aparece em dois títulos e seis vezes consta como palavra-chave. Já o termo 'Avaliação REAd I Porto Alegre - Edição 72 - N 2 - maio/agosto 2012 - p. 468-493 
Gestão e estratégia ambiental: um estudo bibliométrico sobre o interesse do tema nos periódicos acadêmicos brasileiros

Ambiental Estratégica' somente foi encontrado em 2 artigos $(1,8 \%)$ da amostra, não consta em nenhum título e também como palavra-chave. Nenhum artigo citou todos os quatro termos-chave nos textos e somente em 18 deles apareceram citações de três dos quatro termos-chave desta pesquisa.

Para identificação dos periódicos pesquisados foi criado o Quadro 02 que apresenta as 22 publicações nas quais foram encontrados artigos sobre a temática de pesquisa, de um total de 44. O Quadro 2 destaca o título do periódico, classificação conforme Qualis/CAPES, período de pesquisa efetuada, quantidade e percentagem relativa de artigos encontrados com os termos-chave.

Quadro 02: Origem dos artigos da amostra.

\begin{tabular}{|c|c|c|c|c|c|}
\hline \multirow{2}{*}{$\mathbf{N}$} & \multirow{2}{*}{ Periódicos Pesquisados } & \multirow[b]{2}{*}{ Qualis } & \multirow{2}{*}{ Período } & \multicolumn{2}{|c|}{ Artigos } \\
\hline & & & & (Unid) & $(\%)$ \\
\hline 1 & REAd - Rev. Eletrônica de Administração (Online) & $\mathrm{B} 2$ & $2000-2009$ & 17 & 15,04 \\
\hline 2 & G\&P - Gestão \& Produção (UFSCAR. Impresso) & $\mathrm{A} 2$ & $2000-2009$ & 13 & 11,5 \\
\hline 3 & RAP - Rev. de Administração Pública (FGV. Impresso) & $\mathrm{A} 2$ & $2000-2009$ & 13 & 11,5 \\
\hline 4 & CAD - Cadernos EBAPE.BR (FGV) & $\mathrm{B} 1$ & $2003-2009$ & 11 & 9,74 \\
\hline 5 & PROD - Produção (ABEPRO. Impresso) & A2 & $2000-2009$ & 8 & 7,08 \\
\hline 6 & ESA - Engenharia Sanitária e Ambiental (IBES) & A2 & 2004-2009 & 6 & 5,31 \\
\hline 7 & ORA - Organizações Rurais e Agroindustriais (UFLA) & $\mathrm{B} 2$ & $2000-2009$ & 5 & 4,42 \\
\hline 8 & RAM - Rev. de Administração Mackenzie (Impresso) & B1 & $2000-2009$ & 5 & 4,42 \\
\hline 9 & ESTUDOS - Estudos Avançados (USP. Impresso) & A2 & $2000-2009$ & 4 & 3,54 \\
\hline 10 & RAC - Rev. de Administração Contemporânea (Impresso) & B1 & $2000-2009$ & 4 & 3,54 \\
\hline 11 & RAEe - Rev. de Administração de Empresas Eletrônica (Online) & B1 & $2001-2009$ & 4 & 3,54 \\
\hline 12 & RAUSP - Rev. de Administração (FEA-USP) & $\mathrm{B} 2$ & $2000-2009$ & 4 & 3,54 \\
\hline 13 & RCF - Rev. Contabilidade \& Finanças (USP. Impresso) & B1 & 2001-2009 & 4 & 3,54 \\
\hline 14 & O\&S - Organizações \& Sociedade (Impresso) & $\mathrm{B} 2$ & $2000-2009$ & 3 & 2,65 \\
\hline 15 & BAR - Brazilian Administration Review & A2 & 2004-2009 & 2 & 1,77 \\
\hline 16 & BBR - Brazilian Business Review (Online em português.) & $\mathrm{B} 2$ & 2004-2009 & 2 & 1,77 \\
\hline 17 & CI - Contexto Internacional (PUCRJ. Impresso) & B1 & $2000-2009$ & 2 & 1,77 \\
\hline 18 & RAE - Rev. de Administração de Empresas (Impresso) & B1 & $2000-2009$ & 2 & 1,77 \\
\hline & ALETHEIA - Aletheia (ULBRA) & B1 & $2005-2009$ & 1 & 0,89 \\
\hline & BASE - Base (UNISINOS) & $\mathrm{B} 2$ & $2004-2008$ & 1 & 0,89 \\
\hline & I\&S - Informação \& Sociedade (UFPB. Impresso) & $\mathrm{B} 2$ & $2000-2009$ & 1 & 0,89 \\
\hline & REP - Rev. de Economia Política (Impresso) & A2 & $2005-2009$ & 1 & 0,89 \\
\hline \multicolumn{2}{|r|}{ Continua... } & $\ldots$ & $\ldots$ & $\cdots$ & $\ldots$ \\
\hline 44 & VERITAS - Veritas (Porto Alegre) & $\mathrm{B} 2$ & $2005-2009$ & 0 & 0 \\
\hline \multicolumn{4}{|c|}{ TOTAL } & 113 & 100,0 \\
\hline
\end{tabular}

Fonte: elaborado pelos autores, 2010.

REAd I Porto Alegre - Edição 72 - N 2 - maio/agosto 2012 - p. 468-493 
Simone Sehnem, Murilo de Alencar Souza Oliveira, Elaine Ferreira \& Adriana Marques Rossetto

A análise do Quadro 02 mostra que apenas cinco dos periódicos da amostra de pesquisa foram responsáveis por mais da metade $(54,86 \%)$ do total de artigos encontrados com citações dos termos-chave desta pesquisa: REAd - Rev. Eletrônica de Administração (15,04\%), G\&P - Gestão \& Produção (11,50\%), RAP - Rev. de Administração Pública (11,50\%), CAD - Cadernos EBAPE.BR (9,74\%) e PROD - Produção (7,08\%). Foram identificados 47 artigos dentro da amostra em publicações consideradas como A2, 33 artigos em B1 e outros 33 em B2, conforme a classificação Qualis/CAPES 2009. Destaca-se, que não foi identificado artigo em publicação considerada como A1.

Em seguida, é apresentado o Quadro 03 com o volume de artigos selecionados da amostra por periódico e ano de publicação:

Quadro 03: Origem dos artigos da amostra.

\begin{tabular}{|c|c|c|c|c|c|c|c|c|c|c|c|c|}
\hline \multirow[t]{2}{*}{$\mathbf{N}$} & ANO & \multirow[b]{2}{*}{2000} & \multirow[b]{2}{*}{2001} & \multirow[b]{2}{*}{2002} & \multirow[b]{2}{*}{2003} & \multirow[b]{2}{*}{2004} & \multirow[b]{2}{*}{2005} & \multirow[b]{2}{*}{2006} & \multirow[b]{2}{*}{2007} & \multirow[b]{2}{*}{2008} & \multirow[b]{2}{*}{2009} & \multirow[b]{2}{*}{ TOTAL } \\
\hline & PERIÓDICO & & & & & & & & & & & \\
\hline 1 & ALETHEIA & - & - & - & - & - & - & - & - & - & 1 & 1 \\
\hline 2 & BAR & - & - & - & - & - & - & - & 1 & - & 1 & 2 \\
\hline 3 & BASE & - & - & - & - & - & - & 1 & - & - & - & 1 \\
\hline 4 & BBR & - & - & - & - & 1 & - & - & - & - & 1 & 2 \\
\hline 5 & $\mathrm{CI}$ & - & - & - & - & - & - & - & - & 1 & 1 & 2 \\
\hline 6 & CAD & - & - & - & - & 1 & 6 & 1 & 2 & 1 & - & 11 \\
\hline 7 & ESA & - & - & - & - & 1 & 1 & 1 & - & 1 & 2 & 6 \\
\hline 8 & ESTUDOS & - & - & - & - & - & - & - & - & 4 & - & 4 \\
\hline 9 & G\&P & - & - & - & - & - & - & 8 & 1 & 2 & 2 & 13 \\
\hline 10 & $\mathrm{I} \& \mathrm{~S}$ & - & - & - & - & - & - & - & - & 1 & - & 1 \\
\hline 11 & O\&S & - & - & 1 & 1 & - & - & - & - & - & 1 & 3 \\
\hline 12 & ORA & - & - & 1 & 1 & - & 1 & 1 & - & - & 1 & 5 \\
\hline 13 & PROD & - & - & - & - & 1 & 2 & - & 3 & 1 & 1 & 8 \\
\hline 14 & RAC & - & - & - & - & 1 & - & - & - & 1 & 2 & 4 \\
\hline 15 & RAE & 2 & - & - & - & - & - & - & - & - & - & 2 \\
\hline 16 & RAEe & - & - & - & 1 & 1 & 1 & - & - & - & 1 & 4 \\
\hline 17 & RAM & - & 1 & - & - & - & - & 1 & - & - & 3 & 5 \\
\hline 18 & RAP & 2 & 1 & - & 2 & 2 & - & 5 & 1 & - & - & 13 \\
\hline 19 & RAUSP & - & - & - & - & - & 1 & - & 2 & - & 1 & 4 \\
\hline 20 & $\mathrm{RCF}$ & - & 1 & - & - & 1 & - & - & 1 & - & 1 & 4 \\
\hline 21 & REAd & - & 1 & 6 & 1 & 1 & 1 & 2 & - & 1 & 4 & 17 \\
\hline 22 & REP & - & - & - & - & - & - & - & - & - & 1 & 1 \\
\hline & TOTAL & 4 & 4 & 8 & 6 & 10 & 13 & 20 & 11 & 13 & 24 & 113 \\
\hline & $\%$ & 3,54 & 3,54 & 7,08 & 5,31 & $\mathbf{8 , 8 5}$ & 11,50 & 17,70 & $\mathbf{9 , 7 3}$ & 11,50 & 21,24 & 100,00 \\
\hline
\end{tabular}


Gestão e estratégia ambiental: um estudo bibliométrico sobre o interesse do tema nos periódicos acadêmicos brasileiros

Mediante a análise do Quadro 03, verificou-se que houve publicação de artigos selecionados sobre as temáticas deste estudo em todos os anos do período considerado, com um crescimento ocorrido de 2001 a 2006, seguido de redução nos anos de 2007 e 2008 , e novo pico de publicação em 2009. Em 2009, ocorreu também o crescimento de periódicos que abordaram os temas, pois foram encontrados artigos em 16 das 22 publicações componentes da amostra. Cabe destacar, a publicação de edições especiais ou voltadas para a temática ambiental das revistas G\&P - Gestão \& Produção em 2006 e CAD - Cadernos EBAPE.BR em 2005, com 7 e 6 artigos com os termos-chave deste estudo, respectivamente.

Em relação à autoria, 206 autores diferentes foram responsáveis pelos 113 artigos selecionados neste estudo, sendo que destes 53 foram elaborados em dupla (46,9\%), 25 por autoria individual $(22,1 \%), 22$ por trio de autores $(19,5 \%), 9$ por quatro autores $(8,0 \%)$ e apenas 4 tiveram cinco autores (3,5\%). Identificou-se, que apenas 23 autores foram responsáveis por 43 artigos integrantes da amostra de estudo (38\%), tiveram mais de um artigo selecionado, conforme o Quadro 04.

Quadro 04: Autoria dos artigos da amostra.

\begin{tabular}{|c|c|c|c|}
\hline $\mathbf{N}$ & Nome do Autor & Artigos & Periódicos de Publicação (quantidade) \\
\hline 1 & Charbel José Chiappetta Jabbour & 7 & G\&P(2); RAC(1); RAM(1); RAP(1); RAUSP(1); REAd(1) \\
\hline 2 & Fernando César Almada Santos & 7 & G\&P(2); RAC(1); RAM(1); RAP(1); RAUSP(1); REAd(1) \\
\hline 3 & Mônica Cavalcanti Sá de Abreu & 7 & REAd (3); O\&S (1); CAD (1); RAEe (1); G\&P (1) \\
\hline 4 & $\begin{array}{l}\text { José Carlos Lázaro da Silva } \\
\text { Filho }\end{array}$ & 4 & REAd (2); G\&P (1); O\&S (1) \\
\hline 5 & Lucila Maria de Souza Campos & 4 & REAd (3); PROD (1) \\
\hline 6 & Mozar José de Brito & 4 & ORA (2); CAD (1); G\&P (1) \\
\hline 7 & Alexandre de Pádua Carrieri & 3 & BAR (1); RAC (1); RAP (1) \\
\hline 8 & Gregório Jean Varvakis Rados & 3 & CAD (1); RAE-e (1); REAd (1) \\
\hline 9 & $\begin{array}{l}\text { José Antônio Puppim de } \\
\text { Oliveira }\end{array}$ & 3 & RAE-e (1); RAP (1); REAd (1) \\
\hline 10 & José Carlos Barbieri & 3 & RAC (1); RAP (1); REAd (1) \\
\hline 11 & Robson Amâncio & 3 & ORA (2) ; CAD (1) \\
\hline 12 & $\begin{array}{l}\text { Alfredo Rodrigues Leite da } \\
\text { Silva }\end{array}$ & 2 & $\operatorname{BAR}(1) ;$ RAC (1) \\
\hline 13 & Bruno Cals de Oliveira & 2 & G\&P (1); REAd (1) \\
\hline 14 & Celso Funcia Lemme & 2 & REAd (2) \\
\hline 15 & $\begin{array}{l}\text { Hugo Santana de Figueiredo } \\
\text { Júnior }\end{array}$ & 2 & RAE-e (1); REAd (1) \\
\hline & Icaro A. da Cunha & 2 & RAP (2) \\
\hline & José Célio Silveira Andrade & 2 & CI (1); REAd (1) \\
\hline
\end{tabular}

REAd I Porto Alegre - Edição 72 - N 2 - maio/agosto 2012 - p. 468-493 
Simone Sehnem, Murilo de Alencar Souza Oliveira, Elaine Ferreira \& Adriana Marques Rossetto

\begin{tabular}{llll}
\hline 18 & Luis Felipe Nascimento & 2 & O\&S (1); REAd (1) \\
\hline 19 & Maisa de Souza Ribeiro & 2 & RCF (2) \\
\hline 20 & Miguel Afonso Sellitto & 2 & G\&P (1); PROD (1) \\
\hline 21 & Paulo José Silva & 2 & CAD (1); G\&P (1) \\
\hline 22 & Paulo Mauricio Selig & 2 & REAd (2) \\
\hline 23 & Renato J. Orsato & 2 & REAd (2) \\
\hline
\end{tabular}

Fonte: elaborado pelos autores, 2010.

O Quadro 04 apresenta os nomes dos autores que mais publicaram artigos sobre a temática pesquisada no período deste estudo e os periódicos de publicação. Verifica-se pelo Quadro 4 que estes autores citados publicaram em 15 dos 22 periódicos identificados nesta pesquisa, sendo que a REAd - Rev. Eletrônica de Administração publicou artigos de 14 destes autores (66,7\%), seguida de RAP - Rev. de Administração Pública e G\&P - Gestão \& Produção com seis destes autores cada.

Os 4 artigos identificados no ano de 2000 foram elaborados pelos autores Airton Bodstein de Barros e Angela Maria Abreu de Barros; Pedro Penteado de Castro Neto e Paulo Cesar Vaz Guimarães; Philippe Pomier Lyrargues e Carmen Silvia Sanches, tendo sido publicados em edições dos periódicos: RAP - Revista de Administração Pública e RAE Revista de Administração de Empresas. Já no ano de 2001 foram publicados 4 artigos elaborados por 8 autores e publicados em 4 periódicos. No ano de 2002, houve aumento no número de publicações para um total de 8 artigos elaborados por 18 autores, o que evidencia a evolução do interesse para publicar na área ambiental, seja na temática gestão, desempenho, estratégias ou avaliação estratégica. Estes artigos foram publicados em apenas 3 periódicos, com destaque para a REAd - Rev. Eletrônica de Administração com 6 artigos.

Na sequência, no ano de 2003 houve uma queda acentuada no número de publicações, apenas 6, elaboradas por 11 autores e publicadas em 5 periódicos. Contudo, no ano seguinte (2004) houve novo crescimento com 10 artigos publicados, elaborados por 21 autores distintos. Importante salientar que a partir desse ano aumentou para 8 o número de periódicos que passaram a publicar nessa área.

No ano de 2005 ocorreu mais um crescimento no volume de publicações, perfazendo 13 artigos distintos elaborados por 28 autores em 7 periódicos distintos. O periódico Cadernos Ebape liderou naquele ano, ao publicar 6 artigos da área. No ano de 2006, houve mais um crescimento no volume de publicações, totalizando 20 artigos elaborados por 41 autores 
Gestão e estratégia ambiental: um estudo bibliométrico sobre o interesse do tema nos periódicos acadêmicos brasileiros

publicados em 8 periódicos distintos. Destacaram-se os periódicos Gestão \& Produção, RAP e Read, com respectivamente 8,5 e 2 artigos publicados no ano.

$\mathrm{Na}$ sequiência, houve uma queda drástica no ano de 2007, com apenas 11 artigos elaborados por 26 autores e publicados em 7 periódicos distintos. No ano de 2008 teve-se 13 artigos de 28 autores em 9 revistas. E no ano de 2009 foram 24 artigos publicados por 49 autores em 16 periódicos distintos, com destaque para a Read com 4 artigos. Importante salientar que apenas a partir do ano de 2006 foi constatada a repetição de 4 autores que tiveram 2 publicações cada qual naquele ano, sendo: Mozar José de Brito, Charbel José Chiappetta Jabbour, Fernando César Almada Santos e Paulo José Silva. Característica similar foi diagnosticada no ano de 2008, quando ocorreu a repetição de 3 autores: Mônica Cavalcanti Sá de Abreu com 3 artigos, Bruno Cals de Oliveira e José Carlos Lázaro da Silva Filho com 2 artigos cada publicados no ano. Por fim, no ano de 2009 houve a repetição de 5 autores, com destaque para Charbel José Chiappetta Jabbour que publicou 3 artigos identificados na análise. Na sequência, o Gráfico 1 evidencia essa evolução de autores, periódicos e artigos publicados.

Gráfico 1: Evolução dos autores, número de artigos e periódicos que publicaram escritos da area ambiental.

- Número de periódicos $\quad$ Número de artigos publicados - Número de Autores

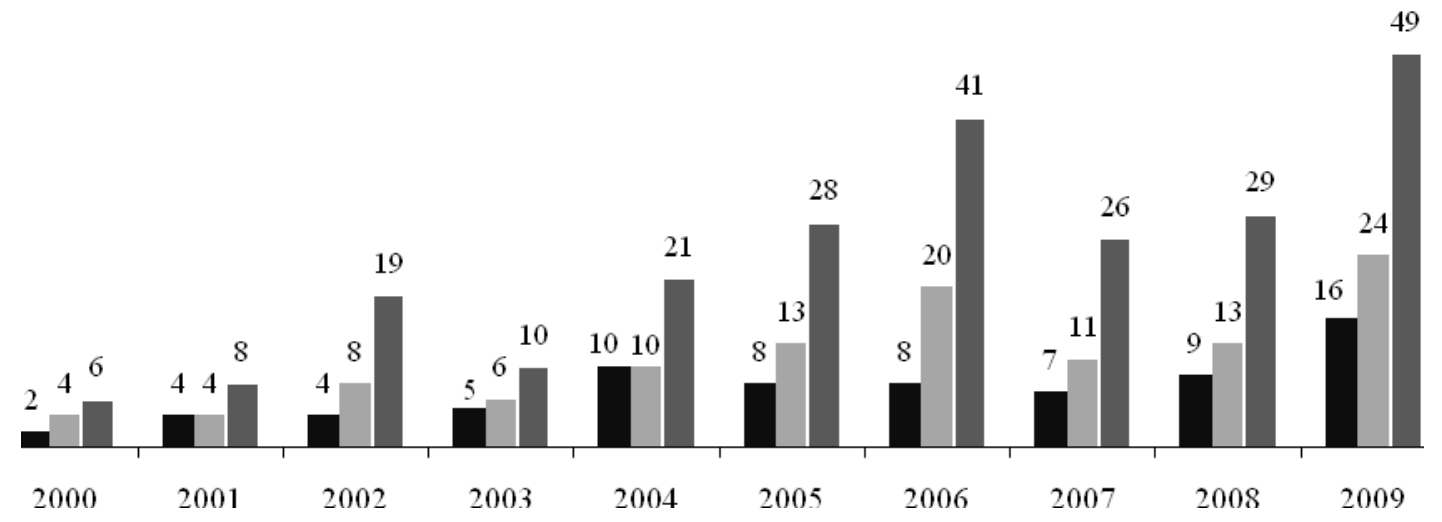

Fonte: dados elaborados pelo autor (2010)

O Gráfico 1 apresenta clara visualização evolutiva de adesão dos autores a publicação de artigos na área ambiental, assim como dos periódicos que publicam nessa área. Constata-se que houve uma ascensão significativa no período analisado de ambos, com pequenas quedas no ano de 2004 e 2008. Portanto, infere-se que a área ambiental está recebendo a atenção dos

REAd I Porto Alegre - Edição 72 - N 2 - maio/agosto 2012 - p. 468-493 
Simone Sehnem, Murilo de Alencar Souza Oliveira, Elaine Ferreira \& Adriana Marques Rossetto

pesquisadores brasileiros, à medida que foi constatado que no ano 2000 foram publicados 4 artigos, escritos por 6 autores e publicados em 2 periódicos, ao passo que no ano de 2009 obteve-se 24 artigos publicados em 16 periódicos e escritos por 49 autores. Isso corresponde a um aumento de $600 \%$ no número de artigos publicados, $816,67 \%$ no número de autores que aderiram a área ambiental para elaborar os seus escritos científicos e $800 \%$ no interesse dos periódicos em aceitar artigos da área ambiental para serem publicados. São indicadores significativos no contexto evolucionário, mas que se tornam pouco significativos no rol de artigos que são publicados ao longo de um ano nos periódicos classificados por Qualis/CAPES.

\section{CONSIDERAÇÕES FINAIS}

O presente artigo tratou de uma análise dos escritos nacionais acerca da gestão e estratégia das organizações nos últimos 10 anos, a partir da identificação de quatro elementos principais: Gestão Ambiental, Estratégia Ambiental, Desempenho Ambiental e Avaliação Estratégica Ambiental. Efetuou-se a descrição dos periódicos de origem, ocorrência dos termos de busca, ano e autoria das publicações.

Dos elementos estudados, constatou-se que a origem das publicações se deu em 22 periódicos, dentre os mais expressivos para a área de Administração, com 47 artigos em publicações consideradas como A2, 33 em B1, bem como em B2, conforme classificação Qualis/CAPES. Os periódicos que mais se destacaram foram: REAd - Rev. Eletrônica de Administração (B2), Gestão \& Produção (A2), RAP - Rev. de Administração Pública (A2), Cadernos EBAPE.BR (B1) e Produção (A2).

O termo-chave 'Gestão Ambiental' aparece no título de 38 dos artigos, é citado como palavra-chave em 64 e consta no corpo de texto de 111. 'Desempenho Ambiental' aparece em metade dos artigos, mas somente consta em 3 títulos e 4 artigos como palavra-chave. 'Estratégia Ambiental' é citado em 20\% dos artigos, consta em 2 títulos e 6 vezes como palavra-chave. Já ‘Avaliação Ambiental Estratégica' foi citado em 2 artigos da amostra.

Observou-se que de 2000 a 2009 houve um crescimento gradativo de periódicos brasileiros e número de artigos publicados sobre a temática ambiental integrada a gestão e estratégia, inclusive com edições especiais. Foram localizados 4 artigos publicados em 2 periódicos no ano de 2000, para um ascensão de 24 artigos publicados em 16 periódicos em 2009. Porém, numa análise macro, a temática ainda não tem difusão significativa nas

REAd I Porto Alegre - Edição 72 - N 2 - maio/agosto 2012 - p. 468-493 
Gestão e estratégia ambiental: um estudo bibliométrico sobre o interesse do tema nos periódicos acadêmicos brasileiros

publicações brasileiras, pois somente houve identificação dos termos-chave propostos na razão de um artigo para cada dez edições analisadas. Infere-se assim, que são recentes as pesquisas sobre a temática da gestão e estratégia ambiental das organizações no país, com poucos artigos publicados, mas que tem ocorrido um bom crescimento, sobretudo na segunda metade da década. Em especial no ano de 2009, houve um crescente interesse dos pesquisadores brasileiros em desenvolver estudos acerca de pelo menos um dos elementos em análise, como eixo central de seus estudos. Isso pode ter relação com o advento da cobrança da sociedade com aspectos concernente ao meio ambiente, dos consumidores, das entidades financeiras e da consciência ambiental que está se criando, pautado nos desastres ecológicos que diversas nações têm sofrido.

Em relação aos autores, foram identificados 206 no total, sendo que $23(11,2 \%)$ participaram com mais de um artigo na amostra, sendo estes os autores de 43 trabalhos (38\%). Charbel José Chiappetta Jabbour, Fernando César Almada Santos e Mônica Cavalcanti Sá de Abreu se destacaram por publicarem cada qual 7 artigos diferentes dentro da amostra. Destaca-se que quase $80 \%$ dos artigos analisados foram elaborados em co-autoria.

A maior contribuição deste artigo consiste em evidenciar as temáticas e tendências de publicação na área, onde está ocorrendo "um renascer" das publicações acerca da gestão ambiental, desempenho ambiental e estratégia ambiental, principalmente, após o declínio ocorrido em 2007. Essa tendência está sendo liderada por autores tradicionais, a exemplo do Charbel José Chiappetta Jabbour que de longa data publica artigos e livros sobre esses assuntos. Por último, pode-se observar que a estratégia ambiental é uma temática que requer estudos analíticos críticos e proativos, que permitam não só a construção de uma reflexão mais profunda, mas também caminhos para a prática. Uma prática capaz de contribuir com a preservação do meio ambiente, e a performance das organizações, no que se refere a otimização dos recursos existentes, rentabilidade para os acionistas e atendimento dos requerimentos de todos os stakeholders.

No que se refere à limitação do estudo, tem-se a restrição da pesquisa aos periódicos nacionais classificados como A1, A2, B1 e B2 pela Qualis/CAPES para a área de Administração, Ciências Contábeis e Turismo, o que retrata uma realidade focada e o emprego apenas da estatística descritiva, que limita a realização de estimativas probabilísticas. Pode-se ampliar a discussão sobre a evolução das publicações da área no mundo, tendo em vista a identificação de uma abordagem e/ou teoria predominante, definição de paradigmas da área recorrentemente citados e verificar o padrão de comportamento dos principais autores da

REAd I Porto Alegre - Edição 72 - N 2 - maio/agosto 2012 - p. 468-493 
Simone Sehnem, Murilo de Alencar Souza Oliveira, Elaine Ferreira \& Adriana Marques Rossetto

área, isto é, quais as temáticas que os mesmos têm usado como referência em seus escritos. Além disso, estudos que possam preencher as lacunas deixadas por esse trabalho, no sentido de aprofundar a análise dos artigos que compõem a amostra analisada. Pode-se também comparar, se o declínio das publicações nas áreas nos anos de 2007 e 2008 em comparação aos outros anos da década analisada está associado a uma possível ascensão de outros paradigmas, como por exemplo, custos ambientais.

Finalmente, os resultados mostram que a temática ambiental recebe atenção da academia brasileira, inclusive com edições especiais para discutir o assunto. Os pressupostos teóricos da gestão ambiental são usados para descrever diferentes realidades organizacionais e geram ensaios teóricos reflexivos. Espera-se que este trabalho possa contribuir, a partir da identificação quantitativa dos artigos, periódicos e autores que citaram os termos-chave de pesquisa (conforme listagem do Apêndice 1), com futuros trabalhos que necessitem fundamentar-se com a produção e publicação nacional acadêmica sobre a temática da questão ambiental relacionada à gestão, estratégia e desempenho organizacionais. Assim como, fica sugestão de estudos qualitativos sobre os objetivos, as contribuições e conclusões dos referidos artigos, bem como sobre a interligação dos termos-chave deste estudo com os propósitos e missão dos periódicos. E ainda, um levantamento do estado da arte internacional dessas temáticas estudadas, para identificar as linhas de pesquisa e grandes tendências internacionais e que possam servir de base de comparação com o estado da arte brasileiro.

\section{REFERÊNCIAS}

AMBEC, S.; LANOIE, P. Does it pay to be Green? A systematic overview. In: Academy of Management Perspectives. London, v.1 n.1 p.45-62, nov. 2008

AZZONE, G; BERTELÈ, U. Exploiting green strategies for competitive advantage. International Journal of Strategic Management. Long Range Planning, city, v. 27, n. 6, p.69-81, 1994.

BELLEN, H. M. van. Indicadores de sustentabilidade: uma análise comparativa. São Paulo: FGV, 2005.

BOCKMAN, S.; RAZZOUK, N.; SIROTNIK, B. The Journal of American Academy of Business, Going Green - From Left to Center Stage: An Empirical Perspective Cambridge, v.14, n.2, p.8-16 mar. 2009 
Gestão e estratégia ambiental: um estudo bibliométrico sobre o interesse do tema nos periódicos acadêmicos brasileiros

CAPES. Coordenação de Aperfeiçoamento de Pessoal de Nível Superior. Disponível em: $<$ http://qualis.capes.gov.br/webqualis/ConsultaListaCompletaPeriodicos.faces $>$. Acesso em: 06/07/2010.

CHRISTMANN, P. Effects of "best practices" of environmental management on cost advantage: the role of complementary assets. The Academy of Management Journal, Briarcliff Manor, v.43, n.4, p. 663-680, aug. 2000.

DALAL-CLAYTON, B.; SADLER, B. Strategic environmental assessment: a rapidly evolving approach. Environmental Planning Issues, n. 18, International institute for environment and development, London, s/v. s/n. p.1-21, 1999.

DONAIRE, D. Gestão ambiental na empresa. São Paulo: Atlas, 1995.

EBENKAMP, B. Green Products Leave Consumers Puzzled. Brandweek, Nova York, 20, p. 1-3, July. 2008.

HART, S. A natural-resource-based view of the firm. The Academy of Management Review, Briarcliff Manor, v.20, n.4, p. 986-1014, oct.1995.

HENRIQUES, I.; SADORSKY, P. The relationship between environmental commitment and managerial perceptions of stakeholders importance. The Academy of Management Journal, Briarcliff Manor, v.42, n.1, p. 87-99, feb. 1999.

HOFFMAN, A. J. Institutional evolution and change: environmentalism and the US chemical industry. The Academy of Management Journal, Briarcliff Manor, v.42, n.4, p. 351-371, aug. 1999.

JABBOUR, C. J. C.; SANTOS, F. C. A.; BARBIERI, J. C. Gestão ambiental empresarial: um levantamento da produção científica brasileira divulgada em periódicos da área de Administração entre 1996 e 2005. Revista de Administração Contemporânea, Curitiba, v.12, n.3, p. 689-715, jul-set. 2008.

MAIMON, D. Eco-estratégia nas empresas brasileiras: realidade ou discurso? Revista de Administração de Empresas. São Paulo: v.34, n.4, p.119-130, jul-ago. 1994.

MIRANDA, N. de; SAMUDIO, E.; DOURADO, F. A estratégia de operações e a variável ambiental. Revista de Administração. São Paulo: v.32, n.1, p. 58-67 jan-mar. 1997.

MÜlleR-PlatenBERG, C. Previsão de impactos: o estudo de impacto ambiental no leste, oeste e sul = experiências no Brasil, na Rússia e na Alemanha. São Paulo: EDUSP, 1998.

NEHRT, C. Timing and intensity effects of environmental investments. Strategic Management Journal, Hoboken, v.17, n.7, p. 535-547, jul. 1996.

NILSSON, M.; DALKMANN, H. Decision making and strategic environmental assessment. Journal of Environmental Assessment Policy and Management. London, v.3, n.3, p.305327, Sept. 2001.

REAd I Porto Alegre - Edição 72 - N 2 - maio/agosto 2012 - p. 468-493 
Simone Sehnem, Murilo de Alencar Souza Oliveira, Elaine Ferreira \& Adriana Marques Rossetto

PARTIDÁRIO, M. do R. Avaliação Ambiental Estratégica. Brasília: MMA, 2002.

PORTER, M.; VAN DER LINDE, C. Toward a new conception of the environmentcompetitiveness relationship. Journal of Economic Perspective, Kansas, v.9 n.4, p. 97-118, 1995.

ROHRICH, S.; CUNHA, J. da. A proposição de uma taxonomia para análise da gestão ambiental no Brasil. Revista de Administração Contemporânea, Curitiba, v.8, n.4, p. 8197, out-dez. 2004.

SANCHES, C. Gestão ambiental proativa. Revista de Administração de Empresas. São Paulo: v.40, n.1, jan-mar. p. 76-87, 2000.

SANCHEZ, L. Avaliação ambiental estratégica e sua aplicação no Brasil. Disponível em: <http://owl.iea.usp.br/iea/aaeartigo.pdf>. Acesso em: 05/03/2010.

VITHESSONTHI, C. Corporate ecological sustainability strategy decisions: the role of attitude towards sustainable development. Journal of Organisational Transformation and Social Change. Bedfordshire, v.6 n.1, pp. 49-64, 2009. 
Gestão e estratégia ambiental: um estudo bibliométrico sobre o interesse do tema nos periódicos acadêmicos brasileiros

\section{APÊEDICE 1 - Relação de artigos identificados na pesquisa (por ano de publicação)}

\begin{tabular}{|c|c|c|c|c|}
\hline $\mathbf{N}$ & Titulo & Autores & Referencia & $\begin{array}{l}\text { Termo- } \\
\text { chave }\end{array}$ \\
\hline 1 & Gestão ambiental proativa & Carmen Silvia Sanches & $\begin{array}{l}\text { RAE, v.40, n.1, p.76- } \\
\text { 87, Jan./Mar. } 2000\end{array}$ & G/D/E \\
\hline 2 & $\begin{array}{l}\text { Sistemas de gerenciamento ambiental, tecnologia } \\
\text { limpa e consumidor verde: a delicada relação } \\
\text { empresa-meio ambiente no ecocapitalismo }\end{array}$ & Philippe Pomier Lyrargues & $\begin{array}{l}\text { RAE, v.40, n.2, p.80- } \\
88 \text {, Abr./Jun. } 2000\end{array}$ & G \\
\hline 3 & $\begin{array}{c}\text { Proposta de um sistema de gestão de recursos } \\
\text { hídricos municipal ou consorciado integrado aos } \\
\text { planos estadual e federal, conforme a Lei } \mathrm{n}^{\circ} \\
9.433 / 97\end{array}$ & $\begin{array}{c}\text { Airton Bodstein de Barros; } \\
\text { Angela Maria Abreu de } \\
\text { Barros }\end{array}$ & $\begin{array}{l}\text { RAP, v. } 34, \text { n.2, p.1-5, } \\
\text { Mar./Abr. } 2000\end{array}$ & G \\
\hline 4 & $\begin{array}{l}\text { A gestão dos resíduos sólidos em São Paulo e o } \\
\text { desafio do desenvolvimento sustentável }\end{array}$ & $\begin{array}{l}\text { Pedro Penteado de Castro } \\
\text { Neto; Paulo Cesar Vaz } \\
\text { Guimarães } \\
\end{array}$ & $\begin{array}{l}\text { RAP, v.34, n.4, p.87- } \\
\text { 104, Jul./Ago. } 2000\end{array}$ & $\mathbf{G}$ \\
\hline 5 & $\begin{array}{l}\text { Contabilidade ambiental: um estudo sobre sua } \\
\text { aplicabilidade em empresas brasileiras }\end{array}$ & $\begin{array}{c}\text { Adalto de Oliveira Santos; } \\
\text { Fernando Benedito da Silva; } \\
\text { Synval de Souza; Marcos } \\
\text { Francisco Rodrigues de Souza }\end{array}$ & $\begin{array}{l}\text { FIPECAFI (RCF), } \\
\text { v.16, n. 27, p. 89-99, } \\
\text { Set./Dez. } 2001\end{array}$ & G \\
\hline 6 & $\begin{array}{l}\text { A influência do fator ecológico na decisão de } \\
\text { compra de bens de conveniência }\end{array}$ & $\begin{array}{l}\text { Sérgio Luis Stirbolov Motta; } \\
\text { Georgio Bedinelli Rossi }\end{array}$ & $\begin{array}{l}\text { RAM, v. 2, n.2, p.109- } \\
130,2001\end{array}$ & G/D \\
\hline 7 & $\begin{array}{l}\text { Certificação ambiental em empresas industriais: o } \\
\text { caso Bayer e os reflexos na conscientização de } \\
\text { seus funcionários e famílias }\end{array}$ & Isnard Marshall Junior & $\begin{array}{l}\text { RAP, v.35, n.3, p.77- } \\
\text { 106, Mai./Jun. } 2001\end{array}$ & $\mathbf{G}$ \\
\hline 8 & $\begin{array}{c}\text { A Qualidade Ambiental em Empresas dos } \\
\text { Setores Primário, Secundário e Terciário no Sul } \\
\text { do Brasil - um estudo de três casos. }\end{array}$ & Luis Felipe Nascimento & $\begin{array}{l}\text { REAd, ed.21, v.7, n.3, } \\
14 \text { p., Mai./Jun. } 2001\end{array}$ & G/D \\
\hline 9 & $\begin{array}{c}\text { A pequena e micro empresa e o meio ambiente: a } \\
\text { percepção dos empresários com relação aos } \\
\text { impactos ambientais }\end{array}$ & $\begin{array}{c}\text { Josivânia Silva Farias; } \\
\text { Rivanda Meira Teixeira }\end{array}$ & $\begin{array}{c}\text { O\&S, v. } 9, \text { n.23, } \\
\text { Jan./Abr. p.1-21, } 2002\end{array}$ & G \\
\hline 10 & $\begin{array}{l}\text { Elementos motivadores da gestão ambiental em } \\
\text { uma unidade produtora leiteira: um estudo de } \\
\text { caso na Holanda }\end{array}$ & $\begin{array}{l}\text { Priscila Borin de Oliveira } \\
\text { Claro; Flávia Luciana Naves } \\
\text { Mafra; Danny Pimentel Claro }\end{array}$ & $\begin{array}{c}\text { Org. Rur. \& Agro., } \\
\text { v.4, n.1, Jan./Jun. p. } 1- \\
13,2002 \\
\end{array}$ & G \\
\hline 11 & $\begin{array}{l}\text { Evolução e condicionantes da gestão ambiental } \\
\text { nas empresas }\end{array}$ & Renato Santos de Souza & $\begin{array}{l}\text { REAd, ed. Esp.30 v.8 } \\
\text { n.6, } 22 \text { p., Nov./Dez. } \\
2002 \\
\end{array}$ & G/D/E \\
\hline 12 & $\begin{array}{l}\text { Integrando ação e comunicação para uma } \\
\text { estratégia de marketing ambiental: o caso } \\
\text { Aracruz celulose } \\
\end{array}$ & $\begin{array}{l}\text { José Antônio Puppim de } \\
\text { Oliveira; Vera Waissman }\end{array}$ & $\begin{array}{l}\text { REAd, ed. Esp. 30, v.8 } \\
\text { n.6, 23p., Nov./Dez. } \\
2002\end{array}$ & G \\
\hline 13 & $\begin{array}{l}\text { Modelo de avaliação da estratégia ambiental: os } \\
\text { perfis de conduta estratégica }\end{array}$ & $\begin{array}{l}\text { Mônica Cavacanti Sá de } \\
\text { Abreu; Hugo Santana de } \\
\text { Figueiredo Júnior; Gregório } \\
\text { Jean Varvakis Rados }\end{array}$ & $\begin{array}{l}\text { REAd, ed. Esp. } 30 \text { v. } 8 \\
\text { n.6, 25p., Nov./Dez. } \\
2002\end{array}$ & G/E/A \\
\hline 14 & $\begin{array}{l}\text { Posicionamento ambiental estratégico, } \\
\text { identificando quando vale a pena investir verde }\end{array}$ & Renato J. Orsato & $\begin{array}{l}\text { REAd, ed. Esp. 30, } \\
\text { v.8, n. 6, } 29 \text { p., } \\
\text { Nov./Dez. } 2002 \\
\end{array}$ & G/D/E \\
\hline 15 & $\begin{array}{l}\text { Relatório sócio-ambiental corporativo e produção } \\
\text { sustentável }\end{array}$ & $\begin{array}{c}\text { Márcia Mara de Oliveira } \\
\text { Marinho; José Célio Silveira } \\
\text { Andrade; Lígia França } \\
\text { Cardoso; Mariene Salatiel } \\
\end{array}$ & $\begin{array}{l}\text { REAd, ed. Esp. } 30 \text { v. } 8 \\
\text { n.6, } 17 \text { p., Nov./Dez. } \\
2002\end{array}$ & G/D \\
\hline 16 & $\begin{array}{c}\text { SGADA - sistema de gestão e avaliação do } \\
\text { desempenho ambiental: A aplicação de um } \\
\text { modelo de SGA que utiliza o Balanced Scorecard } \\
\text { (BSC) }\end{array}$ & $\begin{array}{l}\text { Lucila Maria de Souza } \\
\text { Campos; Paulo Mauricio } \\
\text { Selig }\end{array}$ & $\begin{array}{l}\text { REAd, ed. Esp. } 30 \text { v. } 8 \\
\text { n.6, 23p., Nov./Dez. } \\
2002\end{array}$ & G/D \\
\hline 17 & $\begin{array}{l}\text { Gestão Ambiental: uma crítica sistêmica e outras } \\
\text { alternativas ao "otimismo verde" }\end{array}$ & $\begin{array}{c}\text { João Marcelo Crubellate; } \\
\text { Flávio Carvalho Vasconcelos }\end{array}$ & $\begin{array}{l}\text { O\&S, v.10, n.26, p.84- } \\
\text { 105, Jan./Abr. } 2003\end{array}$ & $\mathbf{G}$ \\
\hline 18 & $\begin{array}{l}\text { Representações sociais sobre os sistemas de } \\
\text { gestão ambiental: uma análise em agroindústrias } \\
\text { do setor lácteo sul-mineiro }\end{array}$ & $\begin{array}{c}\text { Carla Regina de Souza; } \\
\text { Mozar José de Brito; Mônica } \\
\text { de Carvalho Alves Cappelle; } \\
\text { Robson Amâncio }\end{array}$ & $\begin{array}{l}\text { Org. Rur. \& Agro., v. } \\
\text { 5, n. 1, } 27 \text { p., Jan./Jun. } \\
2003\end{array}$ & G \\
\hline
\end{tabular}

REAd I Porto Alegre - Edição 72 - N 2 - maio/agosto 2012 - p. 468-493 


\section{Simone Sehnem, Murilo de Alencar Souza Oliveira, Elaine Ferreira \& Adriana Marques} Rossetto

\begin{tabular}{|c|c|c|c|c|}
\hline 19 & $\begin{array}{c}\text { Gestão ambiental e mudanças da estrutura } \\
\text { organizacional }\end{array}$ & Rosana Icassatti Corazza & $\begin{array}{l}\text { RAE-elet., v. 2, n. } 2 \text {, } \\
23 \text { p., Jul./Dez. } 2003\end{array}$ & G/D \\
\hline 20 & $\begin{array}{c}\text { Insalubridade e Conflito Ambiental: Risco e } \\
\text { Cidadania }\end{array}$ & Icaro Cunha & $\begin{array}{c}\text { RAP, v.37, n.2, p.443- } \\
\text { 57, Mar./Abr. } 2003\end{array}$ & G/D \\
\hline 21 & $\begin{array}{l}\text { Meio Ambiente: Discurso Consistente ou Prática } \\
\text { Vazia? }\end{array}$ & Alexandre de Pádua Carrieri & $\begin{array}{l}\text { RAP, v.37, n.6, } \\
\text { p.1209-1231, } \\
\text { Nov./Dez. } 2003\end{array}$ & G \\
\hline 22 & $\begin{array}{l}\text { The pragmathic challenge of sustainable } \\
\text { development lesons from Shell Canada }\end{array}$ & Renato J. Orsato; Pong Leung & $\begin{array}{l}\text { REAd, ed. Esp.36 v.9 } \\
\text { n.6, 20p., Nov./Dez. } \\
2003\end{array}$ & G/D/E \\
\hline 23 & $\begin{array}{l}\text { A Evidenciação Contábil: Publicação de } \\
\text { Aspectos Sócio-ambientais e Econômico- } \\
\text { Financeiros nas Demonstrações Contábeis }\end{array}$ & $\begin{array}{l}\text { Flávia Zóboli Dalmácio; } \\
\text { Francislene F. M. de Paulo }\end{array}$ & $\begin{array}{l}\text { BBR, v.1, n.2, p. } 74- \\
\text { 90, Jul./Dez. } 2004\end{array}$ & $\mathbf{G}$ \\
\hline 24 & $\begin{array}{c}\text { Indicadores de sustentabilidade - um } \\
\text { levantamento dos principais sistemas de } \\
\text { avaliação }\end{array}$ & Hans Michael Van Bellen & \begin{tabular}{|c|} 
Cad EBAPE, v.2, n.1, \\
14 p. Mar. 2004 \\
\end{tabular} & $\mathbf{G}$ \\
\hline 25 & $\begin{array}{c}\text { O licenciamento ambiental da mineração no } \\
\text { Quadrilátero Ferrífero de Minas Gerais - uma } \\
\text { análise da implementação de medidas de controle } \\
\text { ambiental formuladas em EIAS/RIMAS }\end{array}$ & $\begin{array}{l}\text { José Francisco do Prado } \\
\text { Filho; Marcelo Pereira de } \\
\text { Souza } \\
\end{array}$ & $\begin{array}{l}\text { Eng. San. Amb., v. } 9 \\
\text { n. } 4, \text { p.343-349, } \\
\text { Out./Dez. } 2004\end{array}$ & G/D \\
\hline 26 & $\begin{array}{l}\text { Passivo ambiental: revisão teórica de custos na } \\
\text { indústria do petróleo }\end{array}$ & $\begin{array}{c}\text { Carlos Alberto Bezerra } \\
\text { Galdino; Esmeraldo Macêdo } \\
\text { dos Santos; José Ivam } \\
\text { Pinheiro; Sérgio Marques } \\
\text { Júnior; Rubens Eugênio } \\
\text { Barreto Ramos }\end{array}$ & $\begin{array}{l}\text { Prod., v.14, n.1, p. 54- } \\
\text { 63, Jan./Abr. } 2004\end{array}$ & G/D/E \\
\hline 27 & $\begin{array}{l}\text { A proposição de uma taxonomia para análise da } \\
\text { gestão ambiental no Brasil }\end{array}$ & $\begin{array}{c}\text { Sandra Simm Rohrich; João } \\
\text { Carlos da Cunha } \\
\end{array}$ & \begin{tabular}{|l|} 
RAC, v. 8, n. 4, p. 81- \\
97, Out./Dez. 2004 \\
\end{tabular} & G/D \\
\hline 28 & As pressões ambientais da estrutura da indústria & $\begin{array}{c}\text { Mônica Cavalcanti Sá de } \\
\text { Abreu; Gregório Jean } \\
\text { Varvakis Rados; Hugo } \\
\text { Santana de Figueiredo Junior } \\
\end{array}$ & $\begin{array}{l}\text { RAE-elet., v. 3, n. 2, } \\
\text { Jul./Dez. 22p, } 2004\end{array}$ & G/D/E \\
\hline 29 & $\begin{array}{l}\text { Análise da situação da gestão ambiental nas } \\
\text { indústrias do estado do Rio de Janeiro }\end{array}$ & $\begin{array}{c}\text { José Antônio Puppim de } \\
\text { Oliveira } \\
\end{array}$ & $\begin{array}{c}\text { RAP, v.38, n.2, p.261- } \\
\text { 86, Mar./Abr. } 2004 \\
\end{array}$ & $\mathbf{G}$ \\
\hline 30 & $\begin{array}{c}\text { A educação ambiental e a gestão ambiental em } \\
\text { cursos de graduação em administração: objetivos, } \\
\text { desafios e propostas }\end{array}$ & José Carlos Barbieri & $\begin{array}{l}\text { RAP, v.38, n.6,p. } \\
\text { 919-46, Nov./Dez. } \\
2004\end{array}$ & $\mathbf{G}$ \\
\hline 31 & $\begin{array}{l}\text { Aplicação da contabilidade ambiental na } \\
\text { indústria madeireira }\end{array}$ & $\begin{array}{l}\text { Valdiva Rossato de Souza; } \\
\text { Maisa de Souza Ribeiro }\end{array}$ & $\begin{array}{l}\text { RCF, n.35, p.54-67, } \\
\text { Mai./Ago., } 2004\end{array}$ & $\mathbf{G} / \mathbf{E}$ \\
\hline 32 & $\begin{array}{l}\text { Environmental management systems (EMS) in } \\
\text { the context of small businesses: a study } \\
\text { conducted in the south of Brazil }\end{array}$ & $\begin{array}{l}\text { Lucila Maria de Souza } \\
\text { Campos; Anete Alberton }\end{array}$ & $\begin{array}{l}\text { REAd, ed. Esp. } 42 \\
\text { v.10 n.6, } 32 \text { p., Dez. } \\
2004\end{array}$ & G/D \\
\hline 33 & $\begin{array}{c}\text { Certificações socioambientais: desenvolvimento } \\
\text { sustentável e competitividade da indústria } \\
\text { mineira na Amazônia }\end{array}$ & $\begin{array}{c}\text { Maria Amélia Rodrigues da } \\
\text { Silva; José Augusto } \\
\text { Drummond }\end{array}$ & $\begin{array}{l}\text { Cad EBAPE, v.3, n. 3, } \\
\text { ed. Temática, p.1-21, } \\
2005\end{array}$ & G/D \\
\hline 34 & $\begin{array}{c}\text { Gestão e licenciamento ambiental no Brasil: } \\
\text { modelo de gestão focado na qualidade do meio } \\
\text { ambiente }\end{array}$ & $\begin{array}{l}\text { Roberto Carrilho Padula; } \\
\text { Luciene Pimentel da Silva }\end{array}$ & $\begin{array}{c}\text { Cad EBAPE, v.3, n. 3, } \\
\text { ed. Temática, 15p. } \\
2005\end{array}$ & G \\
\hline 35 & $\begin{array}{l}\text { Modelo Hackefors para obtenção de certificado } \\
\text { ambiental ISO-14.001 em pequenas e médias } \\
\text { empresas - uma discussão sobre sua aplicação em } \\
\text { empresas brasileiras } \\
\end{array}$ & $\begin{array}{c}\text { José Jorge A. Abdalla; Susana } \\
\text { Arcangela Quacchia Feichas }\end{array}$ & $\begin{array}{l}\text { Cad EBAPE, v.3, n. 3, } \\
\text { ed. Temática, } 14 \text { p., } \\
2005\end{array}$ & G \\
\hline 36 & $\begin{array}{l}\text { Motivação e condicionantes para a gestão } \\
\text { ambiental nas maiores indústrias exportadoras do } \\
\text { estado do Ceará }\end{array}$ & $\begin{array}{l}\text { Danielle Batista Coimbra; } \\
\text { Francisco Correa de Oliveira }\end{array}$ & $\begin{array}{l}\text { Cad EBAPE, v.3, n. 3, } \\
\text { ed. Temática, 16p., } \\
2005\end{array}$ & $\mathbf{G}$ \\
\hline 37 & $\begin{array}{c}\text { O Tribunal de Contas da União (TCU) e a gestão } \\
\text { ambiental brasileira - experiência recente }\end{array}$ & $\begin{array}{l}\text { Luiz Henrique Moraes de } \\
\text { Lima }\end{array}$ & $\begin{array}{c}\text { Cad EBAPE, v.3, n. 3, } \\
\text { ed. Temática, 13p., } \\
2005\end{array}$ & G/E/A \\
\hline 38 & $\begin{array}{c}\text { Perspectivas da participação do público através } \\
\text { de ONGs para a gestão ambiental na América } \\
\text { Latina } \\
\end{array}$ & $\begin{array}{l}\text { Gabriel Eduardo Schütz, } \\
\text { Carlos Machado de Freitas; } \\
\text { Sandra Hacon }\end{array}$ & $\begin{array}{c}\text { Cad EBAPE, v.3, n. 3, } \\
\text { ed. Temática, } 15 \mathrm{p} . \\
2005\end{array}$ & G \\
\hline
\end{tabular}

REAd I Porto Alegre - Edição 72 - Nº 2 - maio/agosto 2012 - p. 468-493 
Gestão e estratégia ambiental: um estudo bibliométrico sobre o interesse do tema nos periódicos acadêmicos brasileiros

\begin{tabular}{|c|c|c|c|c|}
\hline 39 & $\begin{array}{c}\text { Alternativas de Minimização de resíduos na } \\
\text { indústria de alimentos da região metropolitana de } \\
\text { Curitiba } \\
\end{array}$ & $\begin{array}{l}\text { Bárbara Zanicotti Leite; } \\
\text { Urivald Pawlowsky. }\end{array}$ & \begin{tabular}{|} 
Eng. San. Amb., v.10, \\
n. 2, p.96-105, \\
Abr./jun. 2005 \\
\end{tabular} & G/D \\
\hline 40 & $\begin{array}{l}\text { Avaliação multicriterial dos impactos ambientais } \\
\text { da suinocultura no Distrito Federal: um estudo de } \\
\text { caso }\end{array}$ & $\begin{array}{c}\text { Ivan Ricardo Gartner; Márcio } \\
\text { Luiz da Silva Gama }\end{array}$ & $\begin{array}{l}\text { Org. Rur. \& Agro., } \\
\text { v.7, n.2, p. } 148-161, \\
\text { Mai./Ago. } 2005\end{array}$ & G/D \\
\hline 41 & $\begin{array}{c}\text { Ferramenta para Tomada de Decisão } \\
\text { Considerando a Interação dos Sistemas de } \\
\text { Produção e o Meio Ambiente }\end{array}$ & $\begin{array}{c}\text { Flávio A. Barrella; Cecília M. } \\
\text { Villas Boas de Almeida; } \\
\text { Biagio F. Giannetti } \\
\end{array}$ & $\begin{array}{l}\text { Prod., v.15, n.1, p. 87- } \\
\text { 101, Jan./Abr. } 2005\end{array}$ & G/D \\
\hline 42 & $\begin{array}{l}\text { Correlação entre gestão da tecnologia e gestão } \\
\text { ambiental nas empresas }\end{array}$ & $\begin{array}{c}\text { José Carlos Teixeira da Silva; } \\
\text { Marcos Schaaf Teixeira da } \\
\text { Silva; Jair Wagner de Souza } \\
\text { Manfrinato } \\
\end{array}$ & $\begin{array}{l}\text { Prod., v. } 15, \text { n.2, p. } \\
\text { 198-220, Mai./Ago. } \\
2005\end{array}$ & G \\
\hline 43 & $\begin{array}{c}\text { Gestão ambiental nas empresas líderes do setor } \\
\text { de telecomunicações no Brasil }\end{array}$ & $\begin{array}{c}\text { Demerval Luiz Polizelli; } \\
\text { Liége Mariel Petroni; Isak } \\
\text { Kruglianskas }\end{array}$ & $\begin{array}{l}\text { R.Adm., v.40, n.4, } \\
\text { p.309-320, } \\
\text { Out./Nov./Dez. } 2005\end{array}$ & G/D \\
\hline 44 & $\begin{array}{c}\text { Uma avaliação dos balanços sociais das } 500 \\
\text { maiores }\end{array}$ & $\begin{array}{l}\text { José Antônio Puppim de } \\
\text { Oliveira }\end{array}$ & $\begin{array}{l}\text { RAE-elet., v. 4, n. 1, } \\
\text { Jan./Jul. } 2005\end{array}$ & $\mathbf{G}$ \\
\hline 45 & $\begin{array}{c}\text { A nova versão da norma ISO 14.001: As } \\
\text { influências presentes no primeiro ciclo revisional } \\
\text { e as mudanças efetuadas }\end{array}$ & $\begin{array}{c}\text { Jorge Emanuel Reis } \\
\text { Cajazeira; José Carlos } \\
\text { Barbieri }\end{array}$ & $\begin{array}{l}\text { REAd, ed. } 48 \text { v. } 11 \text {, } \\
\text { n.6, 26p, Nov-Dez } \\
2005\end{array}$ & G/D \\
\hline 46 & $\begin{array}{c}\text { Análisis de las informaciones ambientales } \\
\text { divulgadas por internet: un estudio comparativo } \\
\text { de empresas del mercado bursátil brasileño, } \\
\text { chileno y español }\end{array}$ & $\begin{array}{l}\text { Darliane Ribeiro Cunha; } \\
\text { Fernando Morales Parada; } \\
\text { Roberto Sergio do } \\
\text { Nascimento } \\
\end{array}$ & $\begin{array}{l}\text { BASE, v.3, n.2, p.200- } \\
\text { 209, Mai./Ago. } 2006 \\
\end{array}$ & G/E \\
\hline 47 & $\begin{array}{c}\text { Políticas e práticas de gestão ambiental: uma } \\
\text { análise da gestão dos resíduos da construção civil } \\
\text { na cidade de Belo Horizonte (MG) }\end{array}$ & $\begin{array}{c}\text { Paulo José Silva; Mozar José } \\
\text { de Brito; Maria Cecília } \\
\text { Pereira; Robson Amâncio } \\
\end{array}$ & \begin{tabular}{|c|} 
Cad EBAPE, v.4, n.3, \\
Out. 25 p, 2006 \\
\end{tabular} & G \\
\hline 48 & $\begin{array}{c}\text { Formulação de uma hipótese global de situação } \\
\text { de impacto para o parque industrial pesqueiro } \\
\text { instalado em Itajaí e Navegantes - SC }\end{array}$ & $\begin{array}{l}\text { Luciana de Carvalho Spillere; } \\
\text { Antonio Carlos Beaumord }\end{array}$ & $\begin{array}{c}\text { Eng. San. Amb., v.11, } \\
\text { n.4, p.380-384, } \\
\text { Out./Dez. } 2006 \\
\end{array}$ & G/D \\
\hline 49 & $\begin{array}{c}\text { Avaliação qualitativa paraconsistente do processo } \\
\text { de implantação de um Sistema de Gestão } \\
\text { Ambiental } \\
\end{array}$ & $\begin{array}{l}\text { Carlos Alberto Ferreira Bispo; } \\
\text { Edson Walmir Cazarini }\end{array}$ & $\begin{array}{l}\text { G\&P, v.13, n.1, p.117- } \\
\text { 127, Jan./Abr. } 2006\end{array}$ & G/D \\
\hline 50 & $\begin{array}{l}\text { Evolução da gestão ambiental na empresa: uma } \\
\text { taxonomia integrada à gestão da produção e de } \\
\text { recursos humanos }\end{array}$ & $\begin{array}{c}\text { Charbel José Chiappetta } \\
\text { Jabbour; Fernando César } \\
\text { Almada Santos } \\
\end{array}$ & $\begin{array}{c}\text { G\&P, v.13, n.3, p.435- } \\
448, \text { Set./Dez. } 2006\end{array}$ & G/D/E \\
\hline 51 & $\begin{array}{c}\text { Há vida após a morte: um (re)pensar estratégico } \\
\text { para o fim da vida das embalagens }\end{array}$ & $\begin{array}{c}\text { Sylmara Lopes Francelino } \\
\text { Gonçalves-Dias }\end{array}$ & $\begin{array}{l}\text { G\&P, v.13, n.3, p.463- } \\
\text { 474, Set./Dez. } 2006\end{array}$ & $\mathbf{G}$ \\
\hline 52 & \begin{tabular}{|c|} 
Processos operacionais e resultados de empresas \\
brasileiras após a certificação ambiental ISO \\
14001 \\
\end{tabular} & $\begin{array}{l}\text { Gilberto Jesus Avila; Ely } \\
\text { Laureano Paiva }\end{array}$ & $\begin{array}{l}\text { G\&P, v.13, n.3, p.475- } \\
\text { 487, Set./Dez. } 2006\end{array}$ & G/D \\
\hline 53 & $\begin{array}{l}\text { Oportunidades tecnológicas e estratégias } \\
\text { concorrenciais de gestão ambiental: o uso } \\
\text { sustentável da biodiversidade brasileira }\end{array}$ & $\begin{array}{c}\text { Ana Flávia Portilho Ferro; } \\
\text { Maria Beatriz Machado } \\
\text { Bonacelli; Ana Lúcia Delgado } \\
\text { Assad } \\
\end{array}$ & $\begin{array}{l}\text { G\&P, v.13, n.3, p.489- } \\
\text { 501, Set./Dez. } 2006\end{array}$ & G/D \\
\hline 54 & $\begin{array}{c}\text { A gestão ambiental em instituições de ensino } \\
\text { superior: modelo para implantação em campus } \\
\text { universitário }\end{array}$ & $\begin{array}{l}\text { Joel Tauchen; Luciana } \\
\text { Londero Brandli }\end{array}$ & $\begin{array}{l}\text { G\&P, v.13, n.3, p.503- } \\
\text { 515, Set./Dez. } 2006\end{array}$ & G/D \\
\hline 55 & $\begin{array}{l}\text { Práticas de Gestão de Resíduos da Construção } \\
\text { Civil: Uma Análise da Inclusão Social de } \\
\text { Carroceiros e Cidadãos Desempregados }\end{array}$ & $\begin{array}{l}\text { Paulo José Silva; Mozar José } \\
\text { de Brito }\end{array}$ & $\begin{array}{l}\text { G\&P, v.13, n.3, p.545- } \\
\text { 556, Set./Dez. } 2006\end{array}$ & $\mathbf{G}$ \\
\hline 56 & $\begin{array}{c}\begin{array}{c}\text { Medição de desempenho ambiental baseada em } \\
\text { método multicriterial de apoio à decisão: estudo } \\
\text { de caso na indústria automotiva }\end{array} \\
\end{array}$ & $\begin{array}{c}\text { Sheila Oliveira de Castro da } \\
\text { Luz; Miguel Afonso Sellitto; } \\
\text { Luciana Paulo Gomes } \\
\end{array}$ & $\begin{array}{c}\text { G\&P, v.13, n.3, p.557- } \\
\text { 570, Set./Dez. } 2006\end{array}$ & G/D/E \\
\hline 57 & $\begin{array}{c}\text { Racionalidade ambiental por parte de produtores } \\
\text { rurais situados na região da nascente do rio } \\
\text { Grande } \\
\end{array}$ & \begin{tabular}{|c|} 
Anna Carolina Salgado \\
Jardim; Robson Amâncio; \\
Marcos Affonso Ortiz Gomes \\
\end{tabular} & $\begin{array}{l}\text { Org. Rur. \& Agro., } \\
\text { v.8, n.1, p. } 105-116, \\
\text { Jan./Abr. } 2006 \\
\end{array}$ & $\mathbf{G}$ \\
\hline 58 & $\begin{array}{l}\text { Administração ecológica: construindo uma } \\
\text { empresa ambiental e socialmente responsável }\end{array}$ & $\begin{array}{c}\text { Simone Bacelar Leal Fereira; } \\
\text { Marie Agnes Chauvel }\end{array}$ & $\begin{array}{l}\text { RAM, v.7, n.4, p.12- } \\
\text { 34, Out./Dez. } 2006\end{array}$ & G \\
\hline
\end{tabular}

REAd I Porto Alegre - Edição 72 - N 2 - maio/agosto 2012 - p. 468-493 


\section{Simone Sehnem, Murilo de Alencar Souza Oliveira, Elaine Ferreira \& Adriana Marques Rossetto}

\begin{tabular}{|c|c|c|c|c|}
\hline 59 & $\begin{array}{l}\text { Gestão ambiental integrada ao desenvolvimento } \\
\text { sustentável: um estudo de caso em Passo Fundo } \\
\text { (RS) }\end{array}$ & $\begin{array}{l}\text { Adriana Marques Rossetto; } \\
\text { Dora Maria Orth; Carlos } \\
\text { Ricardo Rossetto }\end{array}$ & $\begin{array}{l}\text { RAP, v.40, n.5, p.809- } \\
\text { 840, Set./Out. } 2006\end{array}$ & G/D \\
\hline 60 & $\begin{array}{l}\text { Fronteiras da gestão: os conflitos ambientais das } \\
\text { atividades portuárias }\end{array}$ & Icaro A. da Cunha & $\begin{array}{l}\text { RAP, v.40, n.6, } \\
\text { p.1019-1040, } \\
\text { Nov./Dez. } 2006\end{array}$ & $\mathbf{G}$ \\
\hline 61 & $\begin{array}{l}\text { Gestão ambiental portuária: desafios e } \\
\text { possibilidades }\end{array}$ & $\begin{array}{c}\text { Dione Kitzmann; Milton } \\
\text { Asmus }\end{array}$ & $\begin{array}{l}\text { RAP, v.40, n.6, } \\
\text { p.1041-1060, } \\
\text { Nov./Dez. } 2006 \\
\end{array}$ & G/D \\
\hline 62 & $\begin{array}{l}\text { Desafio para a gestão ambiental integrada em } \\
\text { território de fronteira agrícola no oeste do Pará }\end{array}$ & $\begin{array}{l}\text { Cristina Velásquez; André } \\
\text { Villas Boas; Stephen } \\
\text { Schwartzman } \\
\end{array}$ & $\begin{array}{l}\text { RAP, v. } 40, \text { n.6, } \\
\text { p.1061-1075, } \\
\text { Nov./Dez. } 2006 \\
\end{array}$ & G \\
\hline 63 & $\begin{array}{c}\text { A contabilidade da gestão ambiental e sua } \\
\text { dimensão para a transparência empresarial: } \\
\text { estudo de caso de quatro empresas brasileiras } \\
\text { com atuação global } \\
\end{array}$ & $\begin{array}{l}\text { João Eduardo Prudêncio } \\
\text { Tinoco; Léo Tadeu Robles }\end{array}$ & $\begin{array}{l}\text { RAP, v.40, n.6, } \\
\text { p.1077-1096, } \\
\text { Nov./Dez. } 2006\end{array}$ & G/D \\
\hline 64 & $\begin{array}{l}\text { Estudo da complementariedade de sistemas de } \\
\text { gestão ambiental e sistemas de gestão da análise } \\
\text { de perigos e pontos críticos de controle }\end{array}$ & $\begin{array}{l}\text { Marco Túlio Bertolino; Beate } \\
\text { Frank }\end{array}$ & $\begin{array}{l}\text { REAd, ed.51, v.12, } \\
\text { n.3, 26p, Mai./Jun. } \\
2006\end{array}$ & G/D \\
\hline 65 & $\begin{array}{c}\text { A gestão ambiental na empresa por meio da } \\
\text { articulação de equipes:uma perspectiva integrada } \\
\text { e evolutiva }\end{array}$ & $\begin{array}{c}\text { Charbel José Chiappetta } \\
\text { Jabbour; Fernando César } \\
\text { Almada Santos }\end{array}$ & $\begin{array}{l}\text { REAd, ed.52, v.12, n. } \\
\text { 4, 19p. Jul./Ago. } 2006\end{array}$ & $\mathbf{G}$ \\
\hline 66 & $\begin{array}{c}\text { Environmental Discourses in Organizations: the } \\
\text { Case of a Brazilian Mobile Telecommunications } \\
\text { Company }\end{array}$ & $\begin{array}{c}\text { Alexandre de Pádua Carrieri; } \\
\text { Alfredo Rodrigues Leite da } \\
\text { Silva }\end{array}$ & $\begin{array}{l}\text { BAR, v.4, n.3, p. 1-15, } \\
\text { Set./Dez. } 2007\end{array}$ & G/D \\
\hline 67 & $\begin{array}{l}\text { A administração pública e a educação ambiental } \\
\text { no Programa de Gestão Integrada de Resíduos } \\
\text { Sólidos: uma reflexão de uma experiência local }\end{array}$ & $\begin{array}{c}\text { Jane Eyre G. Vieira; Agustina } \\
\text { Rosa Echeverría }\end{array}$ & $\begin{array}{c}\text { Cad EBAPE, v.5, n.1, } \\
\text { 15p, Mar. } 2007\end{array}$ & G \\
\hline 68 & $\begin{array}{c}\text { A situação dos hospitais quanto ao } \\
\text { gerenciamento dos aspectos e impactos } \\
\text { ambientais }\end{array}$ & $\begin{array}{c}\text { Elisete Dahmer Pfitscher; } \\
\text { Bernadete Limongi; Eleonora } \\
\text { Milano Falcão Vieira; } \\
\text { Margarete Petry Pfitscher; } \\
\text { Paulo César Pfitscher } \\
\end{array}$ & $\begin{array}{c}\text { Cad EBAPE, v.5, n.3, } \\
18 \text { p, Set. } 2007 \\
\end{array}$ & G/D/E \\
\hline 69 & $\begin{array}{l}\text { Utilização do método FMEA para avaliação do } \\
\text { risco ambiental }\end{array}$ & $\begin{array}{l}\text { Tatiane Fernandes Zambrano; } \\
\text { Manoel Fernando Martins }\end{array}$ & $\begin{array}{l}\text { G\&P, v.14, n.2, p. } \\
\text { 295-309, Mai./Ago. } \\
2007\end{array}$ & G \\
\hline 70 & $\begin{array}{l}\text { Aplicação da Produção mais Limpa em uma } \\
\text { empresa como ferramenta de melhoria contínua }\end{array}$ & $\begin{array}{c}\text { Denise D. de Medeiros; } \\
\text { Felipe A. Calábria; Gisele C. } \\
\text { S. da Silva; Julio C. G. da } \\
\text { Silva Filho } \\
\end{array}$ & $\begin{array}{l}\text { Prod., v.17, n.1, p. } \\
\text { 109-128, Jan./Abr. } \\
\text { 2007 }\end{array}$ & G/D/E \\
\hline 71 & $\begin{array}{c}\text { Adequação ambiental dos processos usinagem } \\
\text { utilizando produção mais limpa como estratégia } \\
\text { de gestão ambiental }\end{array}$ & $\begin{array}{c}\text { João Fernando Gomes de } \\
\text { Oliveira; Salete Martins Alves }\end{array}$ & $\begin{array}{l}\text { Prod., v.17, n.1, p. } \\
\text { 129-138, Jan./Abr. } \\
2007\end{array}$ & G/E \\
\hline 72 & $\begin{array}{l}\text { Embalagens retornáveis para transporte de bens } \\
\text { manufaturados: um estudo de caso em logística } \\
\text { reversa }\end{array}$ & $\begin{array}{l}\text { Diogo Adlmaier; Miguel } \\
\text { Afonso Sellitto }\end{array}$ & $\begin{array}{l}\text { Prod., v.17, n.2, p. } \\
\text { 395-406, Mai./Ago. } \\
2007\end{array}$ & G/D \\
\hline 73 & $\begin{array}{l}\text { (In) Eficiência econômica e ambiental da } \\
\text { Convenção de Basiléia }\end{array}$ & Marcelo Motta Veiga & $\begin{array}{l}\text { R.Adm., v.42, n.2, } \\
\text { p.128-140, } \\
\text { Abr./Mai./Jun. } 2007\end{array}$ & G/D \\
\hline 74 & $\begin{array}{c}\text { Sustentabilidade na cadeia reversa de } \\
\text { suprimentos: um estudo de caso do Projeto } \\
\text { Plasma } \\
\end{array}$ & $\begin{array}{l}\text { Marcelo Caldeira Pedroso; } \\
\text { Ronaldo Zwicker }\end{array}$ & $\begin{array}{l}\text { R.Adm., v.42, n.4, } \\
\text { p.414-430, } \\
\text { Out./Nov./Dez. } 2007 \\
\end{array}$ & G/D/E \\
\hline 75 & $\begin{array}{l}\text { Desenvolvimento de produtos sustentáveis: o } \\
\text { papel da gestão de pessoas }\end{array}$ & $\begin{array}{c}\text { Charbel José Chiappetta } \\
\text { Jabbour; Fernando César } \\
\text { Almada Santos } \\
\end{array}$ & $\begin{array}{l}\text { RAP, v.41, n.2, p.283- } \\
\text { 307, Mar./Abr. } 2007\end{array}$ & G/D/E \\
\hline 76 & $\begin{array}{l}\text { A uniformidade na evidenciação das informações } \\
\text { ambientais }\end{array}$ & $\begin{array}{l}\text { Rodrigo Simão da Costa; José } \\
\text { Carlos Marion }\end{array}$ & $\begin{array}{l}\text { RCF, n. } 43, \text { p. } 20-33 \text {, } \\
\text { Jan./Abr. } 2007\end{array}$ & G/D \\
\hline 77 & $\begin{array}{l}\text { Modelo de avaliação da estratégia ambiental: } \\
\text { estudos no setor têxtil }\end{array}$ & $\begin{array}{l}\text { Mônica Cavacanti Sá de } \\
\text { Abreu; Sandra Maria dos } \\
\text { Santos; Gregório Jean } \\
\text { Varvakis Rados }\end{array}$ & $\begin{array}{l}\text { Cad EBAPE, v.6, n.1, } \\
24 \text { p, Mar. } 2008\end{array}$ & G/E \\
\hline
\end{tabular}

REAd I Porto Alegre - Edição 72 - N 2 - maio/agosto 2012 - p. 468-493 
Gestão e estratégia ambiental: um estudo bibliométrico sobre o interesse do tema nos periódicos acadêmicos brasileiros

\begin{tabular}{|c|c|c|c|c|}
\hline 78 & $\begin{array}{c}\text { Modelo de Mudanças Climáticas com Gastos } \\
\text { Públicos }\end{array}$ & Pedro Erik Arruda Carneiro & $\begin{array}{l}\text { Cont. Int., v.30, n.1, p. } \\
\text { 49-88, Jan./Abr. } 2008\end{array}$ & G \\
\hline 79 & $\begin{array}{l}\text { ISO 14001: implementar ou não? Uma proposta } \\
\text { para a tomada de decisão }\end{array}$ & $\begin{array}{l}\text { Giuliano Nacarato Moretti; } \\
\text { Klaus Dieter Sautter; Jayme } \\
\text { Augusto Menegassi Azevedo }\end{array}$ & $\begin{array}{c}\text { Eng. San. Amb., v.13, } \\
\text { n.4, p.416-425, } \\
\text { Out./Dez. } 2008\end{array}$ & G/D \\
\hline 80 & Pacto federativo e gestão de águas & $\begin{array}{l}\text { Benedito P. F. Braga; Rodrigo } \\
\text { Flecha; Dilma S. Pena; Jerson } \\
\text { Kelman }\end{array}$ & $\begin{array}{l}\text { Estud. Avanç., v. 22, } \\
\text { n.63, p. 17-42, } \\
\text { Mai./Ago. } 2008\end{array}$ & G \\
\hline 81 & Gestão de bacias hidrográficas & $\begin{array}{l}\text { Monica F. A. Porto; Rubem } \\
\text { La Laina Porto }\end{array}$ & $\begin{array}{l}\text { Estud. Avanç., v. } 22 \text {, } \\
\text { n.63, p. } 43-60 \\
\text { Mai./Ago. } 2008\end{array}$ & $\mathbf{G}$ \\
\hline 82 & $\begin{array}{c}\text { A economia dos recursos hídricos: os desafios da } \\
\text { alocação eficiente de um recurso (cada vez mais) } \\
\text { escasso }\end{array}$ & Antonio Eduardo Lanna & $\begin{array}{l}\text { Estud. Avanç., v. 22, } \\
\text { n.63, p. 113-130, } \\
\text { Mai./Ago. 2008 }\end{array}$ & G \\
\hline 83 & $\begin{array}{c}\text { Um novo paradigma para a gestão de recursos } \\
\text { hídricos }\end{array}$ & Ivanildo Hespanhol & $\begin{array}{l}\text { Estud. Avanç., v. 22, } \\
\text { n.63, p. 131-158, } \\
\text { Mai./Ago. 2008 } \\
\end{array}$ & G \\
\hline 84 & $\begin{array}{l}\text { Panorama de aplicação da norma ISO } 14001 \text { no } \\
\text { Brasil }\end{array}$ & $\begin{array}{l}\text { Felipe Ramalho Pombo; } \\
\text { Alessandra Magrini }\end{array}$ & $\begin{array}{l}\text { G\&P, v.15, n.1, p. } 1- \\
\text { 10, Jan./Abr. } 2008\end{array}$ & G/D \\
\hline 85 & $\begin{array}{c}\text { Perfis estratégicos de conduta social e ambiental: } \\
\text { estudos na indústria têxtil nordestina }\end{array}$ & $\begin{array}{l}\text { Mônica Cavalcanti Sá de } \\
\text { Abreu; José Carlos Lázaro da } \\
\text { Silva Filho; Bruno Cals de } \\
\text { Oliveira; Francisco Leite } \\
\text { Holanda Júnior }\end{array}$ & $\begin{array}{l}\text { G\&P, v.15, n.1, p. } \\
\text { 159-172, Jan./Abr. } \\
2008\end{array}$ & G/D \\
\hline 86 & $\begin{array}{c}\text { Gestión de información para el desarrollo } \\
\text { sostenible }\end{array}$ & $\begin{array}{c}\text { Idalmys Gisela Cruz } \\
\text { Dominguez }\end{array}$ & \begin{tabular}{|c|} 
Inf. \& Soc., v.18, n.2, \\
p. 93-99, Mai./Ago. \\
2008 \\
\end{tabular} & $\mathbf{G}$ \\
\hline 87 & $\begin{array}{l}\text { Indicadores de desempenho dos Sistemas de } \\
\text { Gestão Ambiental (SGA): uma pesquisa teórica }\end{array}$ & $\begin{array}{c}\text { Lucila Maria de Souza } \\
\text { Campos; Daiane Aparecida de } \\
\text { Melo }\end{array}$ & $\begin{array}{l}\text { Prod., v.18, n.3, p. } \\
\text { 540-555, Set./Dez. } \\
2008\end{array}$ & G/D/E \\
\hline 88 & $\begin{array}{l}\text { Gestão ambiental empresarial: um levantamento } \\
\text { da produção científica brasileira divulgada em } \\
\text { periódicos da área de Administração entre } 1996 \text { e } \\
2005 \text {. }\end{array}$ & $\begin{array}{c}\text { Charbel José Chiappetta } \\
\text { Jabbour; Fernando César } \\
\text { Almada Santos; José Carlos } \\
\text { Barbieri }\end{array}$ & $\begin{array}{l}\text { RAC, v.12, n,3, p.689- } \\
\text { 715, Jul./Set. } 2008\end{array}$ & G \\
\hline 89 & $\begin{array}{l}\text { Gestão ambiental e social em empresas de } \\
\text { carcinicultura: estudo de múltiplos casos no } \\
\text { litoral oeste do estado do Ceará }\end{array}$ & $\begin{array}{c}\text { José Carlos Lázaro da Silva } \\
\text { Filho; Mônica Cavalcanti Sá } \\
\text { de Abreu; Norma Beatriz } \\
\text { Camacho Costa; Bruno Cals; } \\
\text { Nicolas Renato Siqueira } \\
\text { Araújo } \\
\end{array}$ & $\begin{array}{l}\text { REAd, ed. } 60, \text { v.14, } \\
\text { n.2, 24p., Mai./Ago. } \\
2008\end{array}$ & $\mathbf{G}$ \\
\hline 90 & $\begin{array}{c}\text { Sistemas de Gestão Ambiental e comportamento } \\
\text { ecológico: uma discussão teórica de suas } \\
\text { possíveis relações }\end{array}$ & $\begin{array}{c}\text { Camila Bolzan de Campos; } \\
\text { Enric Pol }\end{array}$ & $\begin{array}{l}\text { Aletheia, v.29, p.103- } \\
\text { 116, Jan./Jun. } 2009\end{array}$ & G \\
\hline 91 & $\begin{array}{l}\text { A Theoretical Essay on Sustainability and } \\
\text { Environmentally Balanced Output Growth: } \\
\text { Natural Capital, Constrained Depletion of } \\
\text { Resources and Pollution Generation }\end{array}$ & $\begin{array}{l}\text { Augusto Marcos Carvalho de } \\
\text { Sena }\end{array}$ & $\begin{array}{l}\text { BAR, v.6, n.3, p. } 213- \\
\text { 229, Jul./Set. } 2009\end{array}$ & G/D \\
\hline 92 & $\begin{array}{c}\text { A Relação entre o Retorno Anormal e a } \\
\text { Responsabilidade Social e } \\
\text { Ambiental: Um Estudo Empírico na Bovespa no } \\
\text { Período de } 1999 \text { a } 2006\end{array}$ & $\begin{array}{c}\text { Valcemiro Nossa; Jesuína } \\
\text { Figueira Cezar; Annor da } \\
\text { Silva Junior; Ézio Carlos } \\
\text { Silva Baptista; Silvania Neris } \\
\text { Nossa } \\
\end{array}$ & $\begin{array}{l}\text { BBR, v.6, n.2, p. } 121- \\
\text { 136, Mai./Ago. } 2009\end{array}$ & D \\
\hline 93 & $\begin{array}{c}\text { Participação do Setor Privado na governança } \\
\text { Ambiental Global: evolução, contribuições e } \\
\text { obstáculos }\end{array}$ & José Célio Silveira Andrade & $\begin{array}{c}\text { Cont. Int., v.31, n.2, } \\
\text { p.215-250, Mai./Ago. } \\
2009 \\
\end{array}$ & $\mathbf{G}$ \\
\hline 94 & $\begin{array}{l}\text { Estudo dos determinantes da coleta de resíduos } \\
\text { sólidos urbanos em Minas Gerais }\end{array}$ & $\begin{array}{l}\text { Magnus Martins Caldeira; } \\
\text { Sonaly Rezende; Léo Heller }\end{array}$ & $\begin{array}{c}\text { Eng. San. Amb., v.14, } \\
\text { n.3, p.391-400, } \\
\text { Jul./Set. } 2009\end{array}$ & $\mathbf{G}$ \\
\hline 95 & $\begin{array}{c}\text { Indicadores de sustentabilidade para a gestão } \\
\text { municipal de resíduos sólidos urbanos: um estudo } \\
\text { para São Carlos (SP) }\end{array}$ & $\begin{array}{l}\text { Carla Natacha Marcolino } \\
\text { Polaz; Bernardo Arantes do } \\
\text { Nascimento Teixeira }\end{array}$ & \begin{tabular}{|c|} 
Eng. San. Amb., v.14 \\
n.3, p.411-420, \\
Jul./Set. 2009
\end{tabular} & G \\
\hline
\end{tabular}




\section{Simone Sehnem, Murilo de Alencar Souza Oliveira, Elaine Ferreira \& Adriana Marques Rossetto}

\begin{tabular}{|c|c|c|c|c|}
\hline 96 & $\begin{array}{l}\text { Sob os ventos da mudança climática: desafios, } \\
\text { oportunidades e o papel da função produção no } \\
\text { contexto do aquecimento global }\end{array}$ & $\begin{array}{c}\text { Charbel José Chiappetta } \\
\text { Jabbour; Fernando César } \\
\text { Almada Santos }\end{array}$ & $\begin{array}{l}\text { G\&P, v.16, n.1, p. } \\
\text { 111-120, Jan./Mar. } \\
2009\end{array}$ & G/D \\
\hline 97 & $\begin{array}{l}\text { Potencial para implantação da produção mais } \\
\text { limpa em sistemas locais de produção: o polo } \\
\text { joalheiro de São José do Rio Preto }\end{array}$ & $\begin{array}{l}\text { Rosely Mana Domingues; } \\
\text { Sônia Regina Paulino }\end{array}$ & $\begin{array}{l}\text { G\&P, v.16, n.4, p. } \\
\text { 691-704, Out./Dez. } \\
\text { 2009 }\end{array}$ & G/D/E \\
\hline 98 & $\begin{array}{c}\text { Gestão ambiental regional: usando o IAD } \\
\text { Framework de Elinor Ostrom na "análise } \\
\text { política" da gestão ambiental da Região } \\
\text { Metropolitana de Porto Alegre }\end{array}$ & $\begin{array}{l}\text { José Carlos Lázaro da Silva } \\
\text { Filho; Johannes Küchler; Luis } \\
\text { Felipe Nascimento; Mônica } \\
\text { Cavalcanti Sá de Abreu }\end{array}$ & $\begin{array}{l}\text { O\&S, v. } 16-\text { n. } 51, p . \\
\text { 609-627, Out./Dez., } \\
2009\end{array}$ & $\mathbf{G}$ \\
\hline 99 & $\begin{array}{l}\text { Gestão ambiental como prática social em uma } \\
\text { organização produtora de celulose: uma análise } \\
\text { interpretativa }\end{array}$ & $\begin{array}{l}\text { Beatriz Christo Gobbi; Mozar } \\
\text { José de Brito }\end{array}$ & $\begin{array}{l}\text { Org. Rur. \& Agro., } \\
\text { v.11, n.1, Jan./Abr. } \\
2009\end{array}$ & G/D \\
\hline 100 & $\begin{array}{l}\text { Geração de resíduos de madeira e derivados da } \\
\text { indústria moveleira em função das variáveis de } \\
\text { produção }\end{array}$ & $\begin{array}{c}\text { Éverton Hillig; Vania } \\
\text { Elisabete Schneider; Eloide } \\
\text { Teresa Pavoni }\end{array}$ & $\begin{array}{l}\text { Prod., v.19, n.2, p. } \\
\text { 292-303, Mai./Ago. } \\
\text { 2009 }\end{array}$ & G/D \\
\hline 101 & $\begin{array}{c}\text { Sistema contábil para gestão da ecoeficiência } \\
\text { empresarial }\end{array}$ & $\begin{array}{c}\text { Cassio Luiz Vellani; Maísa de } \\
\text { Souza Ribeiro } \\
\end{array}$ & \begin{tabular}{|c|} 
RCF, v. 20, n. 49, p. \\
25-43, Jan./Abr. 2009 \\
\end{tabular} & G/D \\
\hline 102 & $\begin{array}{c}\text { Indicadores sócioambientais: evolução e } \\
\text { perspectivas }\end{array}$ & José Eli da Veiga & $\begin{array}{c}\text { R. Econ. Polít., v. 29, } \\
\text { n. } 4 \text { (116), p. 421-435, } \\
\text { Out./Dez. } 2009 \\
\end{array}$ & D \\
\hline 103 & $\begin{array}{l}\text { Análise do relacionamento entre estágios } \\
\text { evolutivos da gestão ambiental e dimensões de } \\
\text { recursos humanos: estado da arte e survey em } \\
\text { empresas brasileiras }\end{array}$ & $\begin{array}{c}\text { Charbel José Chiappetta } \\
\text { Jabbour; Fernando César } \\
\text { Almada Santos; Marcelo } \\
\text { Seido Nagano }\end{array}$ & $\begin{array}{l}\text { R.Adm., v.44, n.4, } \\
\text { p.342-364, } \\
\text { Out./Nov./Dez. } 2009\end{array}$ & G/D/E \\
\hline 104 & $\begin{array}{c}\text { O Tema da Proteção Ambiental Incorporado nos } \\
\text { Discursos da Responsabilidade Social } \\
\text { Corporativa } \\
\end{array}$ & $\begin{array}{l}\text { Alexandre de Pádua Carrieri; } \\
\text { Alfredo Rodrigues Leite da } \\
\text { Silva; Thiago Duarte Pimentel } \\
\end{array}$ & $\begin{array}{l}\text { RAC, v.13, n. 1, p. 1- } \\
\text { 16, Jan./Mar. } 2009\end{array}$ & $\mathbf{G}$ \\
\hline 105 & $\begin{array}{c}\text { Estratégias para Compatibilizar Desenvolvimento } \\
\text { Econômico e Gestão Ambiental numa Atividade } \\
\text { Produtiva Local }\end{array}$ & $\begin{array}{l}\text { Maria Gracinda Carvalho } \\
\text { Teixeira; Eliane da Silva } \\
\text { Bessa } \\
\end{array}$ & $\begin{array}{l}\text { RAC, v. 13, ed. Esp., } \\
\text { p.1-18, Jun. } 2009\end{array}$ & G/D \\
\hline 106 & $\begin{array}{c}\text { Consciência ambiental: um estudo exploratório } \\
\text { sobre suas implicações para o ensino de } \\
\text { administração }\end{array}$ & $\begin{array}{l}\text { Sylmara Lopes Francelino } \\
\text { Gonçalves-Dias; Armindo dos } \\
\text { Santos de Sousa Teodósio; } \\
\text { Selma Carvalho; Hermes } \\
\text { Moretti Ribeiro da Silva } \\
\end{array}$ & $\begin{array}{l}\text { RAE-elet., v. 8, n. 1, } \\
\text { Art. 10, Jan./Jun. } 2009\end{array}$ & G \\
\hline 107 & $\begin{array}{l}\text { A análise do processo de implantação das normas } \\
\text { de sustentabilidade empresarial: um estudo de } \\
\text { caso em uma agroindústria frigorífica de bovinos }\end{array}$ & $\begin{array}{c}\text { Geraldino Carneiro de } \\
\text { Araújo; Paulo Sergio Miranda } \\
\text { Mendonça } \\
\end{array}$ & $\begin{array}{l}\text { RAM, v.10, n.2, p. } 31- \\
\text { 56, Mar./Abr. } 2009\end{array}$ & $\mathbf{G}$ \\
\hline 108 & $\begin{array}{l}\text { Estudos de caso sobre custos ambientais: ênfase } \\
\text { nos procedimentos metodológicos }\end{array}$ & Laura Calixto & \begin{tabular}{|c|} 
RAM, v. 10, n.2, p. \\
87-109, Mar./Abr. \\
2009 \\
\end{tabular} & $\mathbf{G}$ \\
\hline 109 & $\begin{array}{l}\text { A importância dos fatores humanos no } \\
\text { desenvolvimento de produtos com elevado } \\
\text { desempenho ambiental: estudo de casos }\end{array}$ & \begin{tabular}{|c|} 
Charbel José Chiappetta \\
Jabbour; Fernando César \\
Almada Santos; Ana Beatriz \\
Lopes de Sousa Jabbour \\
\end{tabular} & $\begin{array}{l}\text { RAM, v.10, n.4, p. 32- } \\
\text { 56, Jul./Ago. 2009, }\end{array}$ & G/D \\
\hline 110 & $\begin{array}{c}\text { As empresas com certificação ISO } 14001 \text { são } \\
\text { mais rentáveis? Uma abordagem em companhias } \\
\text { abertas no Brasil }\end{array}$ & \begin{tabular}{|c|} 
Lucila Maria de Souza \\
Campos; Cleci Grzebieluckas; \\
Paulo Mauricio Selig
\end{tabular} & $\begin{array}{c}\text { REAd, ed. 62, v.15, } \\
\text { n.1, 24p., Jan./Abr } \\
2009\end{array}$ & G/D/E \\
\hline 111 & $\begin{array}{c}\text { Participação, integração e paradigmas como } \\
\text { variáveis de análise da gestão ambiental regional } \\
\text { através dos comitês de gerenciamento de bacias } \\
\text { hidrográficas }\end{array}$ & $\begin{array}{c}\text { José Carlos Lázaro da Silva } \\
\text { Filho; Mônica Cavalcanti Sá } \\
\text { de Abreu }\end{array}$ & $\begin{array}{l}\text { REAd, ed.63, v. } 15 \text {, } \\
\text { n.2, 27p., Mai./Ago. } \\
2009\end{array}$ & G \\
\hline 112 & $\begin{array}{c}\text { Investimento socialmente responsável no } \\
\text { mercado de capitais: análise do desempenho de } \\
\text { índices internacionais e fundos de ações } \\
\text { brasileiros que consideram questões ambientais e } \\
\text { sociais }\end{array}$ & $\begin{array}{l}\text { Fabiana Moreno de Campos; } \\
\text { Celso Funcia Lemme }\end{array}$ & $\begin{array}{l}\text { REAd, ed.63, v. } 15 \text {, } \\
\text { n.2, 21p., Mai./Ago. } \\
2009\end{array}$ & G \\
\hline 113 & \begin{tabular}{|c|} 
Um exame da relação entre o nível de \\
internacionalização e a comunicação ambiental \\
nas grandes empresas brasileiras de capital aberto
\end{tabular} & $\begin{array}{l}\text { Débora Guimarães Masullo; } \\
\text { Celso Funcia Lemme }\end{array}$ & $\begin{array}{l}\text { REAd, ed. 64, v.15, } \\
\text { n.3, 24p., Set./Dez. } \\
2009\end{array}$ & G/D \\
\hline
\end{tabular}

Legenda: $\mathrm{G}=$ Gestão Ambiental; $\mathrm{D}$ = Desempenho Ambiental; $\mathrm{E}=$ Estratégia Ambiental; $\mathrm{A}$ = Avaliação Ambiental Estratégica

REAd I Porto Alegre - Edição 72 - N 2 - maio/agosto 2012 - p. 468-493 